\title{
LA EXTRACCIÓN DE LA PIEDRA DE LA MEMORIA. UNA ESTÉTICA SUBALTERNA BAJO EL FRANOUISMO: EL CASO DEL CANTERO JOSÉ MEIJÓN
} The Extraction of the Stone of Memory. Subaltern aesthetics under
Francisco Franco's dictatorship: the works of mason José Meijón

\author{
Germán Labrador Méndez* \\ Princeton University (EE.UU.)
}

\section{Palabras clave \\ Subalternidad Memoria histórica Franquismo Art brut}

\section{Keywords}

Subalternity Historical memory Francoism Art brut

\begin{abstract}
RESUMEN: Este artículo presenta el caso del cantero José Meijón, un artista psiquiatrizado que, durante cincuenta años, produjo una fascinante obra en piedra alrededor de la villa de Marín (Pontevedra, Galicia). Su arte invisible es hoy un vibrante testimonio de la represión franquista en su localidad y de las problemáticas de la memoria de la Guerra Civil. Planteamos una reconstrucción de su corpus y una serie de estrategias de lectura de sus obras en relación con las transformaciones modernizadoras que experimentó su medio entre 1931 y 1980. Para ello, desplegaré la biografía y la leyenda oral del personaje, en relación con su obra, sobre el espacio social y cultural al que pertenecía, para desde allí plantear una estrategia de lectura orgánica que integre al tiempo biografía, historia, estética y espacio. A partir de ahi, ofrezco una breve historia política de las transformaciones en el territorio de Marín desde la Guerra Civil como marco general de comprensión del arte de Meijón. En la tercera sección, trataremos de poner su obra en diálogo con las tradiciones rupestres que cita y cuyos códigos actualiza en clave de vanguardia, como espacio de escritura memorial del rico universo político y religioso local (republicano, trabajador y protestante) destruído durante la Guerra Civil. Por último, me interesa plantear las tensiones que la obra de Meijón plantea con los llamados procesos de recuperación de la memoria histórica actuales.
\end{abstract}

ABSTRACT: This article offers a case study after the works by mason José Meijón, an artist subjected to psychiatric discipline that, during fifty years, developed a fascinating project over the stones around the town of Marin (Pontevedra, Galicia). His invisible art represents today a telling testimony of the repression under Francisco Franco's dictatorship and of the problems related to the Spanish Civil War's memories. I will defend a possible reconstruction of Meijon's artistic corpus and a number of reading strategies to offer a comprehension of his work in relation to authoritarian developmentalist politics between 1931 and 1980. In order to do so, I will display Meijon's biography and oral legend in relation to his works and to the social and cultural space from which they originate. My goal is to offer a comprehensive reading taking into account history, biography, aesthetics and the space as a whole. In section two, I will present a short political history of Marin's territory and its transformations since the Spanish Civil War, to provide a general frame for Meijon's art. Section three, interrogates his art in relation to the local prehistoric engravers that he explicitly quotes, updating their codes in terms of avant-garde aesthetics. By means of this gesture, Meijon is organizing a memorial writing for the rich religious (protestant) and political (working-class and Republican) local democratic universe, destroyed during the war. Finally, I am interested in focusing political tensions that Meijon's works arise today face to our so-called processes for the recovering of historical memory.

* Correspondencia a / Correspondence to: Germán Labrador Méndez. University of Princeton (USA), Department of Spanish and Portuguese, Princeton (NJ 08544-Estados Unidos) - labrador@princeton.edu - http://orcid.org/0000-0003-4183-4776.

Cómo citar / How to cite: Labrador Méndez, Germán (2021). "La extracción de la piedra de la memoria. Una estética subalterna bajo el franquismo: el caso del cantero José Meijón». Papeles del CEIC, vol. 2021/1, papel 241, 1-28. (http://dx.doi.org/10.1387/pceic.21787).

Fecha de recepción: junio, 2020 / Fecha aceptación: enero, 2021

ISSN 1695-6494 / ㄷ 2021 UPV/EHU 
Las páginas siguientes ${ }^{1}$ se hacen cargo de un caso de estudio singular: la obra de José Meijón Area (1899-1980), un cantero de la localidad pontevedresa de Marín que, durante décadas, y con vocación artística, llenó su región de enigmáticas inscripciones, ganándose la fama de demente.

\section{Figura 1}

José Meijón. Plaza de la Constitución, Friso Oriental. Túnel de la Rúa da Calzada debajo de la Rúa da Ponte (Marín, Pontevedra). Detalle

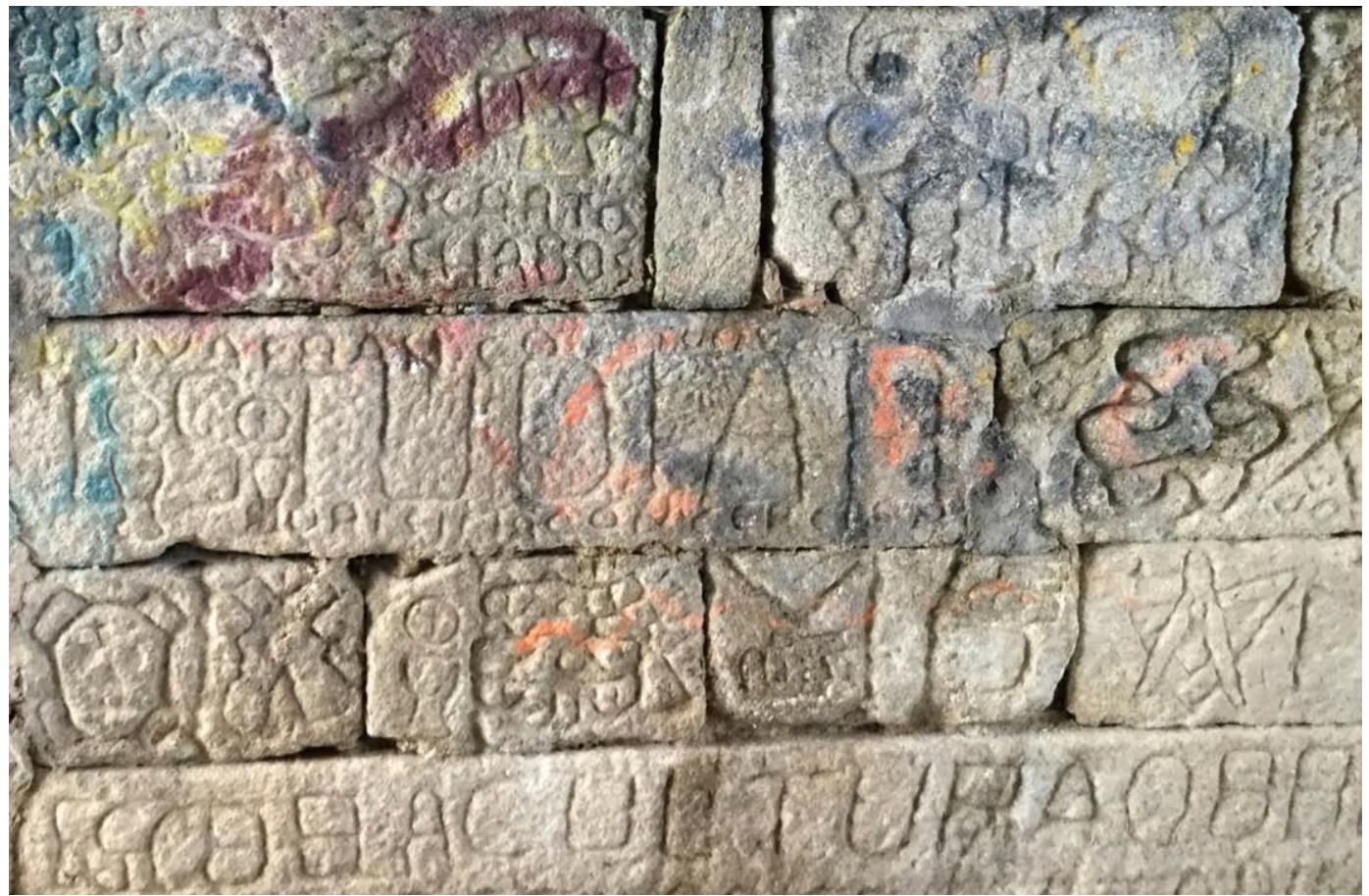

Fotografía del autor.

1 Aqui presento los primeros resultados en castellano de una investigación larga y compleja, que habrá de dar lugar a una pequeña monografía en un futuro cercano. Quiero celebrar el compromiso, paciencia y generosidad de las muchas personas que me proporcionaron pistas y datos clave, como Celso Milleiro, Queta Mola, Alberto Mallo, Elena Aguete y Guillermo Meijón Couselo. También el entusiasmo de Laura Freire, Rafael SánchezMateos y mis padres que, con infinita paciencia, se contagiaron de mi urgencia hasta perderse ellos también "por esos montes de dios y de Pepito». Agradezco a Cruz su ayuda secreta, y reconozco que estas líneas no se habrian dado jamás sin el aliento de María do Cebreiro Rábade, quien me prestó sus manos y ojos para completarlas. En el verano de 2017, Agar Ledo y Miguel Anxo Rodríguez fueron el detonante de este estudio al invitarme a participar en una reunión modélica, el Seminario de Nuevas Narrativas de Historia del Arte, celebrado en el Centro Galego de Arte Contemporáneo en Santiago, el día de Acción de Gracias de 2017. Una formulación primera de esa intervención apareció en gallego en la revista Grial (57: 222, 2019: 34-53). Igualmente, versiones preliminares de estas páginas fueron presentadas en el seminario de doctorado de Jesús Izquierdo en la Universidad Autónoma de Madrid en enero de 2018 y en el congreso Bodies Out Of Place celebrado en San Sebastián en julio de 2018, por invitación de Francisco Ferrándiz. En el mes de abril de 2019, compartí este trabajo en una charla pública en Duke University, gracias a la hospitalidad de Jose María Rodríguez, y también en el coloquio Writing Insurgencies with José Rabasa, dirigido por Nicole Legnani, en el Departament of Spanish and Portuguese de Princeton University. Agradecezco a los organizadores de tales eventos, y a los participantes, sus muchos comentarios, que han enriquecido estas páginas. También a mis estudiantes de SPA239 y SPA228, que en los dos últimos años han mostrado un interés desmedido por la vida y milagros del singular cantero José Meijón. Mención aparte merece el convite de Gabriel Gatti al Seminario Permanente de Mundo(s) de Víctimas en el Centro de Estudios sobre la Identidad Colectiva de la Universidad de País Vasco a comienzos de 2019. En Bilbo pude presenciar el rito de Santa Águeda, el despertar la tierra con cantos y golpes de bastones. En recuerdo de aquellas horas felices, vaya este texto que tuvo a bien pedirme. 
Aqui pretendo afrontar la lectura de sus grabados rupestres con todo su enigma formal y su crudeza expresiva, sin recurrir a justificaciones patológicas. Defenderé que el suyo es un arte que debe entenderse desde una sensibilidad hermenéutica cercana a los estudios subalternos, en el cruce entre estética y antropología, y más allá de los dispositivos disciplinarios de la psiquiatría, la historia del arte, o el psicoanálisis. Para argumentarlo, desplegaré los grabados de Meijón sobre su territorio y en su contexto histórico, hasta volverlos de algún modo legibles, defendiendo el sentido restitutivo de este gesto hermenéutico.

Cuarenta años después de su fallecimiento, el caso de Meijón es, al tiempo, el de un ser olvidado por la historia pero intensamente recordado entre los suyos. En su villa natal se le nombra aún con entusiasmo y su arte resulta todavía visible por calles y caminos. Pero aunque vecinos y seguidores vean en sus inscripciones fundamentalmente la obra de un lunático, me interesa cuestionar esa supuesta falta de significado. Lo haré en relación con las lógicas propias del espacio y del tiempo en los que Meijón desarrolló la mayor parte de su arte, esto es, en el entorno de una villa portuaria gallega durante la posguerra franquista. Desde allí cabe comprender su mundo expresivo en relación con las heridas locales de la Guerra Civil y las transformaciones desarrollistas que esta impuso en su comarca. Además, siendo el municipio de Marín conocido por su extraordinario legado arqueológico, es posible leer las inscripciones meijónicas como una suerte de petroglifos modernos a partir del arte propiamente prehistórico que las rodea.

Meijón dialogaba formal y conceptualmente con los grabados neolíticos a través de la tradición de la cantería gallega, pero lo hacía desde las claves vanguardistas de su tiempo, incorporando al repertorio prehistórico símbolos contemporáneos, fundamentalmente asociados con el impacto de la Guerra Civil en su comarca. En relación con la historia, el arte meijónico adquiere un carácter ritual, a partir de estrategias conmemorativas que aquí desvelaremos. A lo largo de cuatro décadas, su corpus se irá elaborando en resistencia sorda contra los símbolos de la dictadura y frente al modelo de desarrollo territorial impuesto por la misma, convocando una memoria disociada del universo cultural local - republicano, socialista y protestante- desaparecido tras la represión de 1936. Más allá del interés específico del caso concreto de Meijón, y de los desafíos interpretativos que su obra implica, el desvelamiento de su arte nos permite reflexionar sobre la conformación histórica de nuestra mirada estética, y sobre las consecuencias políticas y comunitarias de ser conscientes o no de la construcción contingente de la misma.

\section{JOSÉ MEIJÓN Y EL POEMA MEMORIAL DEL MARÍN DE POSGUERRA}

Comencemos por presentar al personaje objeto de este estudio, el albañil y cantero José Meijón Area, vecino de la villa portuaria de Marín, situada en la parte estrecha de la orilla sur de la ría de Pontevedra, a menos de diez kilómetros de la capital de provincia.

A Meijón sus vecinos le llamaban (y aún llaman) cariñosamente Pepito, y lo consideraban una persona en la niebla, de pensamiento oscuro pero gran determinación y mentalmente inestable. Nos lo confirman algunos testimonios recogidos entre sus convecinos en el verano de 2017 ("no se metía con nadie», «no hacía mal ninguno», "él no andaba muy bien de la cabeza, ¿no sabes?»). Pero Meijón era algo más que el «loco del pueblo». Era un obsesivo trabajador de la piedra que, durante al menos cincuenta años, desarrolló un inquietante arte en el pai- 
saje de su parroquia. Su recurrente golpear las rocas no solo se debía a las fuerzas oscuras de la locura, sino también a una innegable pulsión estética que sus vecinos reconocen y cuya singularidad o belleza celebran ("dejó la piedra de la calle muy hermosa», afirmó un lugareño), sin atribuirle un sentido profundo. La positiva consideración de muchos de los suyos, sin embargo, no le ha valido a la obra de Meijón atención institucional alguna, ni a nivel local, ni autonómico. Ninguna institución artística se ha interesado tampoco. Y ello, por más que sería sencillo comprender su propuesta en relación con proyectos de intervención paisajística afines que le fueron estrictamente contemporáneos, como aquellos del land-art (Pérez Ocaña, 2011). Sus modos son legibles desde una estética margivagante (Ramírez, 2013), o desde la noción de «espacios singulares» (Hernández, 2013). Pero, a pesar de la invisibilidad de la obra de Meijón, y de su falta de inscripción en los registros estéticos contemporáneos hegemónicos - como el land art-o menores - como el patrimonio rupestre-, Pepito realizó un programa artístico sofisticado sin formación académica, ni ayuda, y en una situación cercana a la marginalidad. Ello no significa que no tuviera acceso a otros conocimientos y tradiciones con cultivo local, de tipo popular o gremial, pues, de un lado, Meijón provenía de una familia de canteros y aprendió las técnicas y repertorios de tal oficio y, por otro, Pepito tuvo acceso a la riqueza arqueológica de su región, a sus conjuntos de grabados prehistóricos al aire libre. De tal modo, más que considerarlo como un land-artist, cabe pensar en Meijón como un petroglifeiro. Y tiene sentido, ya que, en los alrededores de Marín, en las lomas del monte Pituco $y$, sobre todo, en las fincas junto al mar de Pontevedra, se encuentran algunas de las inscripciones rupestres más importantes de Europa, las de la Eira dos Mouros, la fabulosa piedra de los laberintos de Mogor alrededor de la cual Meijón diseña varias intervenciones.

Figura 2

Carné de identidad, José Meijón Area. Retrato fotográfico

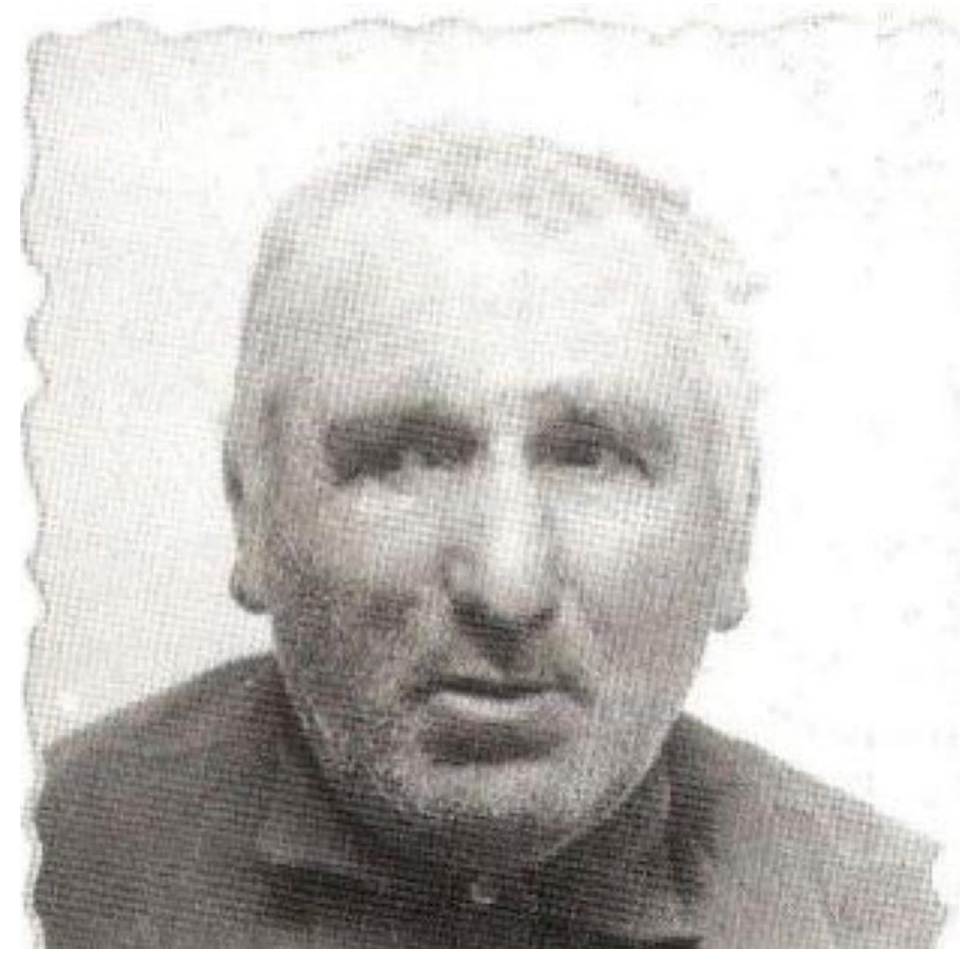

Fuente: Guillermo Antón Meijón Couselo. 
De este modo, en intenso diálogo, Meijón incorpora la cantería neolítica a su propio imaginario, representándose como el heredero moderno de los escultores castrexos (los supuestos pobladores galaicos anteriores a la conquista romana). El suyo quiere ser un arte de petroglifos de vanguardia. Busca confrontar los símbolos religiosos y militares que definieron el siglo $x x$, tal y como él lo vivió, con las antiguas formas de los mouros (pobladores míticos del folclore gallego), cifrando así, en el territorio, sus propios dramas biográficos y los de su comunidad. A través del arte, parecería inscribir la violencia cultural propia de la era moderna en una larga duración que permite comprenderla como enigma. La suya fue una tarea de décadas, en las que Meijón desarrolló su personal gramática de glifos y palabras, elaborando una verdadera teología política llena de angustia y lucha, donde se deja leer la memoria de una comunidad destruida en el tiempo.

Digo que se deja leer porque, para sus vecinos, esos golpes rituales en la roca hoy carecen propiamente de sentido. Tampoco sabemos si hace sesenta $u$ ochenta años, cuando las obras de Pepito se esculpieron, eran más transparentes. Ahí comienza el trabajo de la crítica, porque es posible vislumbrar - al menos, en una parte - los significados ocultos de estos grabados, desenredando las capas culturales que los componen, mediante los perfiles de los mundos a los que refieren y los pasajes históricos en los que adquieren sentido. Para que este trabajo hermenéutico pueda darse, para que las misteriosas runas de Pepito brillen de tal modo que hoy se hagan legibles, deben ser comprendidas a la luz de los procesos políticos y económicos que atravesaron el territorio donde su autor las inscribía. Interpretar y recordar críticamente es ya un primer gesto decolonial. Por eso, resulta necesario convocar las palabras escritas en las piedras de Meijón en relación con las violencias y las intervenciones que articulan los paisajes de su Marín natal, desde la oscuridad de los olvidos, pervivencias y fuerzas que los forman.

Incluso si el trabajo de José Meijón Area es opaco y su biografía impresionista, la leyenda del personaje sigue siendo localmente intensa. Cuarenta años después de su fallecimiento, $\mathrm{Pe}$ pito todavía está presente en la memoria del pueblo, como un vecino pintoresco con rasgos de criatura del folklore. Muchos lo recuerdan pasando sus días en el monte o dibujando en las rocas con un martillo y un buril por las calles y paredes del Marín de posguerra. Otros, que no lo conocieron, aún así heredaron los cuentos de un Meijón que salía temprano de la casa y pasaba las horas por montañas, playas, castros y corredoiras [caminos de piedra hundidos entre fincas]. No era muy hablador, pero no se metía con nadie. Los niños lo acosaban para burlarse de él y Pepito los amenazaba con su martillo. Se hacía sus propios trajes con cartón y alambres, porque la ropa no le duraba por el roce con las rocas. Sus herramientas las llevaba entre el pecho y la blusa. No se le entendía al hablar, pero tuvo conversación intensa con las piedras. Se dice que prefería la intimidad con las rocas a la de las personas, pero aún así aceptaba un cigarro de buen grado. Vivió y murió soltero, a cargo de sus hermanas. Estas se ganaban la vida vendiendo material de construcción. En la casa familiar, Meijón hizo un museo de esculturas de cristos y palomas, destruido poco después tras su muerte. Hay algunos detalles menores sobre su figura, pero lo ya dicho constituye la parte principal de la leyenda.

La fuerza viva del recuerdo de Meijón contrasta con la inexactitud que rodea su biografía, casi tan anónima como la de cualquier hijo de sus vecinos. Aún así, los pocos datos conocidos $-y$ documentables - son valiosos, comenzando por las fechas de nacimiento y muerte, 18991980, que enmarcan su vida en los dos supuestos extremos de la historia española contemporánea. Para el metarrelato principal de nación, entre tales años se produciría el gran viaje colectivo de la modernización, y así, Pepito nacería tras la pérdida de las últimas colonias exteriores - las capitulaciones del 1898 fueron firmadas en un pazo en Lourizán, a sólo cinco ki- 
lómetros de la casa de los Meijón-, y moriría en el actual régimen democrático. En tal intervalo, la nación supuestamente triunfaría sobre una larga historia de confrontación, pobreza y aislamiento, finalmente redimida gracias a la feliz comparecencia de las naciones europeas bajo el paraguas de los Estados Unidos y la atenta mirada de la OTAN. La normalización como mito, diría Elena Delgado (2014), constituye la figura central de esta narrativa, que nos permite imaginar en términos de realización nacional la incorporación progresiva a un tejido geopolítico imperial y a una economía capitalista. Un proceso que ha implicado elevar el nivel de vida y las libertades de partes significativas de la población, lo que, a su vez, impide percibir la parte colonial de su estructura. El efecto de estas transformaciones socioeconómicas sirvió, a la vez, para difuminar en el largo plazo los efectos de la violencia fundacional de la Guerra Civil, prolongada a través del régimen de Franco, en lo que constituye el otro fenómeno clave del siglo pasado. Esta violencia, a su vez, se convierte en motor del trabajo de Meijón. Y, aunque en el relato modernizador triunfante en democracia, los breves interludios utópicos, democráticos, emancipadores y populares, anteriores a la muerte de Franco, tengan muy poco espacio, aún así dejarán una huella profunda, decisiva, en el imaginario de Pepito. De este modo, la vida y la obra de Meijón atraviesan y cuestionan el gran relato histórico nacional del pasado siglo.

En el curso de su vida, Meijón vivió una guerra colonial, una breve República, la Guerra Civil, dos dictaduras y la transición democrática. Con la excepción de las campañas coloniales en el Riff, donde la memoria popular lo coloca como un soldado recluta (aunque su expediente militar nos advierte que fue declarado no apto para la guerra al ser llamado a filas), la experiencia de estos procesos se hará desde Marín, con sus manifestaciones locales y consecuencias específicas, dejando registro de las mismas en rocas. Pero no es solo la historia de los sistemas políticos y las guerras lo que emerge entre las letras meijónicas. También la historia del capital, y de su capacidad de intervenir en el territorio y el paisaje. Las transformaciones desarrollistas modificaron todo el diseño del área de Marín, en su economía, estructura, urbanismo y población durante más de un siglo. Y, correlativamente, en el trabajo de Pepito podremos leer las diferentes fases de este desarrollo, fundamentalmente extractivo: primero la militarización, después la electrificación y la industrialización y, finalmente, la financiarización. A través de la imposición de infraestructura pesada - puertos y carreteras-, cultivos extractivos - eucalipto- y fuerzas de ocupación - guardia civil, iglesia y marina-, el mundo de Meijón cambiaría radicalmente en el transcurso de su vida, con una violencia que hace irreconocibles las figuras que lo identificaban.

La obra de Meijón habla de estos tránsitos en clave traumática. 0 , más específicamente, habla de las rupturas que preceden a estos tránsitos, en las que se apoyan las formas de gobierno y de dominación que reorganizan el territorio y descomponen el paisaje. Lo hará desde las coordenadas propias de su parroquia. Es alli donde su arte adquiere una proyección comunitaria. Pero Pepito no es exactamente un portavoz: sus grabados aparentemente nada dicen que su comunidad quiera leer 0 , al menos, que sepa traducir correctamente. En cierto nivel, no importa, porque al cabo no se trata solo de lo que Meijón dice, sino de dónde y cómo lo dice. Su obra adquiere su carácter público y compartido al darse en el territorio parroquial. Desde alli opera como una oración de piedra.

Porque, a pesar de su irreductible singularidad, hasta psiquiátrica, a pesar de las experiencias de alienación mental de las que también habla su arte, la inscripción meijónica, en tanto que práctica, como marca antes que como texto, implica decisivamente el mundo social y vecinal del que proviene. Opera como una intervención estética situada. No obedece solo a un mandato individual, a la manifestación de una conciencia ajena a la razón o al lenguaje. Las mar- 
cas de Meijón se colectivizan en las mismas piedras que materialmente constituyen los espacios públicos de su comunidad. Y, para ello, no importa cuánto su escritura acuse el filtro de la locura o de la falta de significado que la ronda, al menos, en apariencia, porque la oscuridad y la locura son también, como veremos, poderosos refugios para los sentimientos políticos. Pero sin entrar aún en sus significados, los petroglifos de Meijón guardan, desde su materialidad, la época desde la que fueron inscritos. Duran en la conciencia colectiva como símbolos asociados a una experiencia histórica, casi como la decantación formal de la misma. Los grabados meijónicos forman como una película de historia sobre rocas de la región, una costra de signos decididamente no contemporánea, pero no tan vieja como para carecer de pasado, o como para pensarse como algo que estuvo allí desde siempre. Lo suficientemente joven pero aún no tan antiguo como para nadie recuerde un momento en que no existía aún, el trabajo de Meijón tiene, y aún es, una forma de memoria colectiva que condensa ritualmente la experiencia histórica de la región en el siglo pasado.

Porque cabe interrogar el arte de Meijón en su dimensión ritual, como la obra de un hombre consagrado, que pertenece y no a su comunidad, y que dedica lo mejor de sus días a la tarea interminable de inscribir sus angustias y visiones en las piedras de la región, haciendo como una magia común, elaborando en su trabajo sobre la piedra una memoria colectiva y traumática que señala las heridas que cruzan el territorio y los recuerdos de su gente, el lugar donde se forma su pliegue. Son palabras de un peligro, los símbolos del secreto que Meijón tartamudea en la piedra lenta y recurrentemente, inscribiendo los mismos trazos una y otra vez, en repeticiones sin aparente causa - triadas, duplicaciones, recurrencias de unos a otros lugares-y variaciones mínimas.

\section{Figura 3}

José Meijón. Plaza de la Constitución, Friso Oriental. Túnel de la Rúa da Calzada debajo de la Rúa da Ponte (Marín, Pontevedra)

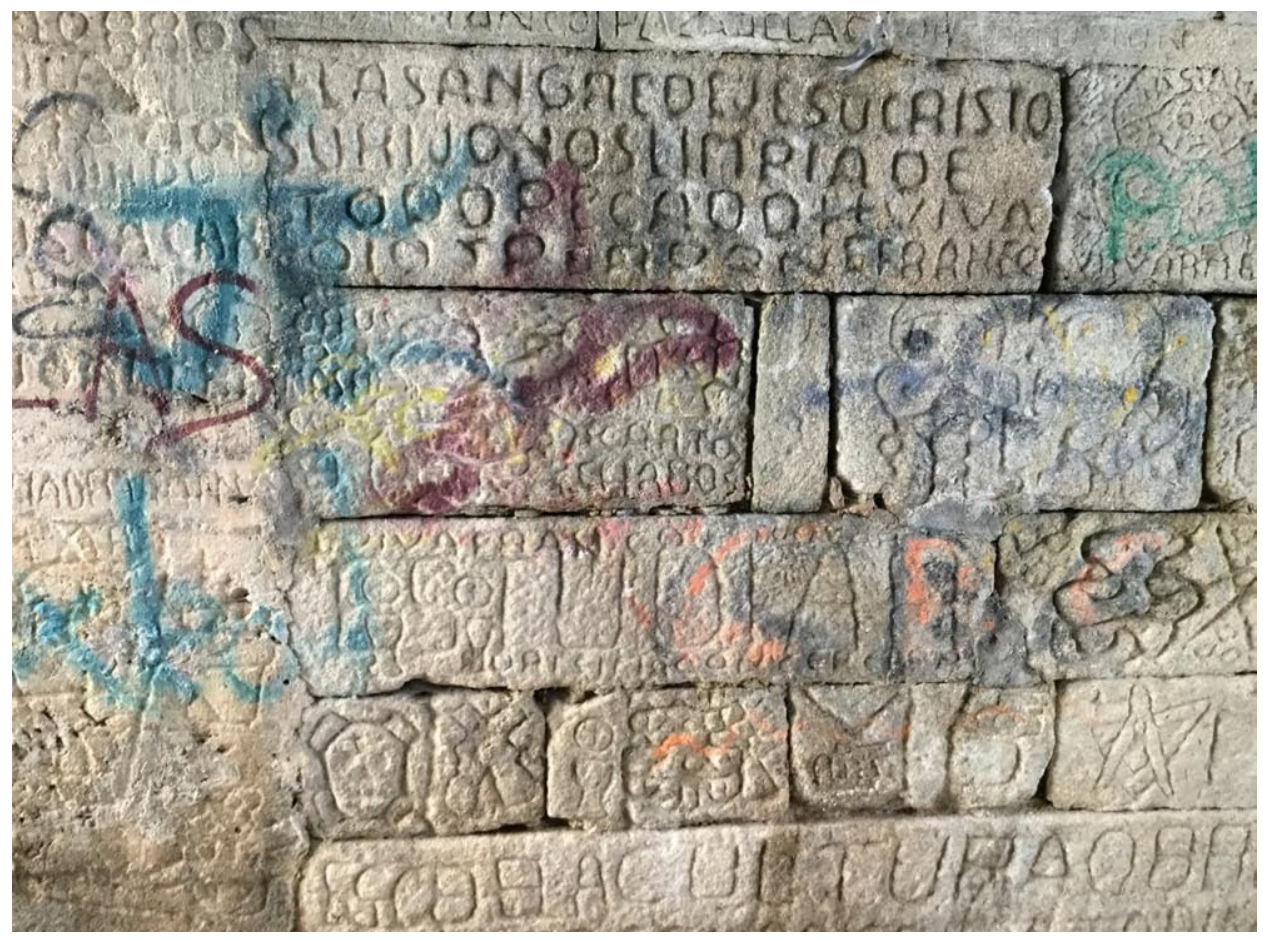

Fotografía del autor. 
Durante más de cinco décadas, Meijón escribió su delirante texto junto a las piedras de la región. Un poema esquizoide que, aparentemente, carece de sentido.

Aunque mi intención sea argumentar que sí lo tiene.

El primer acto interpretativo es siempre una lectura.

Y todas marcas en serie, aisladas sobre una superficie, forman un poema.

Un poema a la vista de cualquiera.

FRANCO PLAZA DE LA CONSTITUCIÓN

LA SANGRE DE JESUCRISTO
SU HIJO NOS LIMPIA DE
$\begin{array}{ll}\text { TODO PECADO } & + \text { VIVA } \\ \text { DIOS PERDÓN } & \text { FRANCO }\end{array}$

CRUZ [CRUZ]

DE

JOSÉ [VIRGEL DEL CARTOS

CARMEN CON CHABOS NIÑO]

VIVA FRANCO

ESTUDIAR

[ostia y [ostia y

copón] copón]
[FIGURA DE

DIABLO]

VIVA ARMADA

[SOLDADO

CAÍDO

CON ANCLA]
[SOLDADO

CON

ARMA]

[MUERTE] [FUSILES] [ostia y [figura] [ilegible] [HERMANDAD copón]

[FIGURA

QUE REZA]

ESCUELACULTURAOBRERA

Esta pieza forma parte de un extenso friso en relieve que cubre, desde el piso hasta el techo a ambos lados, el interior de un túnel en el centro de Marín. El túnel impidió que la construcción de una carretera elevada interrumpiese la Rúa da Calzada, una de las arterias del casco antiguo y la calle donde vivía Meijón. Era por lo tanto una intervención al lado de su casa y una de las escasas obras suyas realizadas directamente sobre cemento en el espacio público (la inmensa mayoría de sus trabajos fueron sobre piedra). La transcripción de dicho texto, compuesto de grabados, ilustraciones y versos, representa desde el inicio un desafío crítico. Requiere, primero, respetar los dos niveles de significado donde funciona el poema, el de las palabras y el de los símbolos, marcando las intersecciones de su código alfabético y pictográfico. Leer las letras de Meijón no es siempre fácil, pero descifrar sus jeroglíficos lo es aún menos, por lo que incluyo entre paréntesis mis propuestas para la transcripción verbal de sus iconos, basadas en un trabajo de análisis y comparación del corpus de su trabajo, realizado ya extensamente pero aún pendiente de sistematización. Los iconos de Meijón se refieren a fuertes conceptos culturales, deidades o personas, simbolos y emblemas, pero otras veces actúan más como sustitutos de palabras o ideas, a la manera de una escritura primitiva de logogramas que, a veces, se asemeja a la tradición maya o egipcia.

En su conjunto, el texto transcrito aquí nos habla de religión (católica) y política (franquista), pero también de sociedad civil. Así, de un lado, encontramos menciones a la Eucaristía, al sa- 
crificio, al perdón y a la divinidad. También aparece la Virgen del Carmen, patrona del mar, y de la Armada, condición especialmente importante esta última, en relación con la presencia local de la Escuela Naval, donde estudian los futuros oficiales de la Marina española. Diosa de los océanos, entonces, y de sus ejércitos, la Virgen del Carmen nos recuerda la imposibilidad de delinear claramente la religión y la política cuando se encuentran, como en las rocas de Meijón, bajo la dictadura de Franco. Otros versos traen voces marciales, algunas dedicadas al Caudillo, los nombres de algún general o la presencia enigmática de los caídos en las aguas. Hay figuras que llevan el ancla como Cristo su cruz, su instrumento de martirio.

Pero hay algo más, porque, junto con el catolicismo de Franco, en los grabados se puede escuchar un universo distante y delicado de referentes, que alcanza presencias difuminadas en la memoria. Porque también en estos versículos aparecen instituciones locales democráticas, proletarias, anteriores a la Guerra Civil, como la Hermandad de los Canteros y la Escuela de los Trabajadores, proyectos que se refieren al mundo socialista y republicano. De pronto, como una promesa, con una determinación que parece guiarlo en medio del horror generalizado plasmado en la pared, se dice ESTUDIAR. También hay otra referencia interesante dentro de este poema, una palabra que cruza los tres mundos (franquismo, religión y república), la palabra "dinero». Representa una mención menor, si se compara con el espacio que ocupan estudiar o la escuela sindical, siendo estas las dos nociones con el tamaño de fuente más grande en el conjunto y quizás, por ello, también más importantes. Su tamaño resulta significativo, considerando, por ejemplo, que el símbolo de la Eucaristía no ocupa más espacio que la primera letra del verbo estudiar.

Además de los versos que aquí transcribo, en ese túnel hay otros. Muchos. Son similares a los mencionados. Comparten formas y tonos y mundos de referencia. Cruces de piedra. Tumbas. Sacerdotes y demonios. Rifles y calaveras. Símbolos falangistas. Saludos republicanos. Sangre, dolor y pecado. Forman un universo de luto y generales franquistas, voces que piden salvación y monstruos. Otro pequeños fragmentos flotan sobre ellos, hechos de una materia política diferente, que resiste la muerte. Las ruinas de Meijón cuelgan de las paredes de las piezas del túnel del mundo hasta convertirlo en un pasaje, una cápsula del tiempo. Cruzarlo es cruzar por medio de una canción llena de furia, tan cercana a nosotros, y muda, ininteligible, por ello.

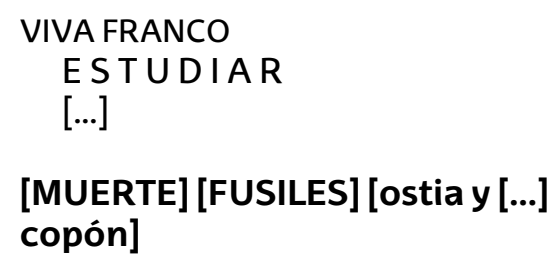

\section{[FIGURA}

QUE REZA]

[HERMANDAD

DE LOS CANTEROS]

ESCUELACULTURAOBRERA

La cabeza de José Meijón era una cámara de ecos que podemos atravesar en el espacio de un túnel.

En su interior se escucha un poema terrible, esquizofrénico.

El poema de la represión franquista en la villa de Marín.

Mientras, por ese túnel, pasa también el tiempo. 


\section{UNA PSICO-GEOGRAFÍA POLITICA DE MARÍN: LAS MEMORIAS EN LA SUPERFICIE Y LAS SUPERFICIES DE LA MEMORIA}

El texto anterior no deja dudas sobre la importancia que tenía el lenguaje franquista para José Meijón o, al menos, sobre la importancia que este le atribuía al universo teológico de la dictadura. En los símbolos comentados, Pepito capturó los principales vectores de un discurso que conocemos como nacional-catolicismo y que, en relación con las necesidades militares de la Guerra Civil y la gestión de la victoria de Franco, promovía el culto religioso alrededor del ejército, supuesto salvador de la nación española. Que Meijón remita en sus poemas una y otra vez al lenguaje franquista militante no convierte automáticamente a Meijón en franquista, católico o españolista. Tal vez lo convierta en testigo. Porque el universo del nacional-catolicismo no es el único que Meijón habita en sus sueños escultóricos. Como pequeños fragmentos de antaño, luciérnagas en la roca, con su lenguaje de orden y disciplina, vienen palabras ajenas, y aún enemigas, a la lengua del régimen, propias de colectivos e instituciones, como sindicatos o fraternidades, reprimidas durante la Guerra Civil. Es el caso de la ya mencionada Escuela de Cultura Obrera (Milleiro y Moreira, 2017), en la que el propio José Meijón habría aprendido su oficio de cantero. Son islas de otro tiempo, las que flotan en la sangre del poema conmemorativo, y desde ellas se afirma una lucha que trasciende los grabados en piedra para preguntar qué queda tras el horror y la violencia franquista de una guerra en la cual, en Galicia, hubo retaguardia tan solo.

Ese es el corte principal que estructura la producción meijónica, el gesto de regresar, una y otra vez, a la roca para volver a inscribir la ruptura inicial de los sentidos que 1936 resume como fecha. Es, tal vez, una forma de intentar conjurarla. El trabajo de Meijón en favor de la memoria -memoria de los mundos desvanecidos por la guerra, pero también memoria de la guerra como trauma y memoria del inicio del régimen que de aquella proviene- remite a la dimensión radical del conflicto, a su importancia como base de un nuevo ordenamiento del territorio del estado. Desde ahí, el contexto local de un pequeño pueblo marinero permite vincular lo micro y lo macro de una historia que, con variantes locales significativas, no dejó de suceder en cada pueblo y cada región del solar ibérico, a veces incluso con sus propios testigos y guardianes del lenguaje de los vencidos (Piedras Monroy, 2012).

Por eso, el caso de Meijón no es un ejemplo menor, sino uno concreto, es decir, un ejemplo en el que la concreción histórica nos ofrece una escala para el inmenso, pero aún así medible, impacto de un proceso histórico traumático, que podemos calificar — con Marx y Harvey-de acumulación desposesiva. Porque la guerra opera liberando una violencia sistémica que priva a amplios sectores de la población de sus derechos sobre territorios, recursos y saberes (de la toponimia al uso del espacio urbano o al acceso a tierras comunales...). Esos espacios, bienes y conocimientos pasan a ser administrados por nuevos agentes e instituciones, lo que progresivamente refuerza su poder y prestigio sociales, frente a la pérdida de relevancia de los sectores desposeídos. Este proceso adquiere localmente además un marcado carácter extractivo, es decir, se dirige a obtener el control de materias primas y recursos naturales, vitales, que se comercializan sin transformar, con un importante coste ambiental, y escaso retorno comunitario. Cuando visualizamos este proceso a través de la construcción de una carretera por medio de un arenal, o mediante la ocupación de kilómetros de costa, vemos cómo detrás de la aparente anécdota están operando estructuralmente formas de gobierno colonial. Porque es evidente que durante la guerra el ejército franquista ocupará el polígono naval de Marín y militarizará la villa a continuación, destruyendo la institucionalidad republicana y re- 
primiendo la sociedad civil a través de actos de terror (como robos y saqueos, torturas y fusilamientos...), pero lo que no es tan evidente es que el territorio municipal se va a reordenar territorial y culturalmente a partir de esa ocupación.

La tarea artística y ritual de José Meijón emerge en la encrucijada necropolítica del régimen, es decir, en relación con los procedimientos por los cuales el franquismo como orden pudo crear poder y gobierno desde su gestión pública de la muerte, como base para la edificación de su poder. Si la noción de «necropolítica» de Mbembé (2003) es hoy uno de los términos clave a propósito de la relación entre violencia y autoridad, se debe en parte a la ubicuidad de una experiencia - la de estado de excepción como normalidad instituida - que fue escasamente atendida durante mucho tiempo, por parecer restringida a la realidad colonial. Con Mbembé (2001), en la colonia, el derecho a la vida no está garantizado, porque se ha impuesto una forma de gobierno basada en el poder de dar la muerte. Para ello, es necesario espectacularizar la destrucción de las formas de poder comunitario y los medios naturales preexistentes, es decir, las redes y recursos que mantienen a los individuos con vida, exponiéndolos asi a la vulnerabilidad absoluta.

El término "necropolítica» se ha extendido a partir de la globalización de las prácticas de medicina forense en relación con la expansión de los marcos de derechos humanos y las políticas de memoria (Ferrándiz, Robben y Wilson, 2015). Aunque el término se propone para hablar de las formas de gobernanza en los territorios del sur global, parecería adecuarse bien históricamente a los modos propios de los estados de emergencia (golpes de estado, genocidios, expulsiones) que implican la promoción organizada de terror y de muerte, inscribiendo la violencia en el territorio, a través de estrategias de terrorismo de estado, como la diseminación de fosas comunes. Este gobierno de la muerte, de los cadáveres, de sus éxodos y entierros irregulares, de los espacios donde esa muerte se dispersa y difumina, es precisamente lo que hace posible extender culturalmente las lógicas genocidas de la guerra civil durante la posguerra.

Como argumenta Ferrándiz (2014), la presencia silenciosa de cuerpos represaliados en el territorio, los inscribe en un tiempo-sin-tiempo, tiempo simbólico, no cronológico, vinculado a la estructura colectiva del trauma. La exposición al terror cierra el acceso al espacio público, y correlativamente impide la expresión pública del duelo, haciendo inviable la reorganización política de la comunidad. Eso es así en teoría, porque cada forma de dominación conoce sus resistencias y negociaciones, sin importar cuán violentas puedan ser unas y modestas las otras. Aquí, en nuestro contexto, el nuevo orden que se funda con las masacres de los 36 conectará en un mismo ciclo una larga posguerra, los años del desarrollismo económico franquista y aún la transición democrática, como argumentaré con respecto a las estrategias de carácter conmemorativo que Meijón desarrolla. En sus petroglifos, se visibiliza una y otra vez precisamente aquella violencia invisibilizada. Su escritura rupestre monumentaliza aquello que debería operar en silencio para ser más efectivo, recordándonos la presencia de lo que se pretende olvidado. Así, los grabados meijónicos ofrecen su oposición sorda, popular, a los intentos franquistas de naturalizar las formas de gobierno colonial definitivamente impuestas sobre la región a partir del verano de 1936, y a los ciclos de intervención territorial que las suceden.

El territorio donde ocurre esta violencia tiene, en nuestro caso, dimensiones específicas, y en ellas se juegan las formas de olvido y memoria que aquí estudio. Como indiqué, el espacio donde Pepito, a lo largo de varias décadas, produjo una inmensa obra fue, paradójicamente, muy limitado. Y expuesto: su legado vive al aire libre hoy, sin que ninguna institución se haya molestado hasta la fecha en interpretar o preservar su trabajo en el paisaje. Por el contrario, su producción ha estado, y todavía está, sujeta a erosión continua, amenazada por construc- 
ciones públicas y privadas. Escritos en el viejo empedrado de Marín, muchos glifos de Meijón acabaron en los muros de contención de algunos chalets de la costa. Las extensiones de los cementerios municipales o la construcción de nuevas iglesias han destruido otra parte del corpus de Meijón. En los muros de la playa de Portocelo versos de Meijón se pueden contemplar dislocados como si el azar barajara estas runas secretas.

El abandono patrimonial se acompaña de un desinterés crítico. Además de algunos vecinos entusiastas, del valioso trabajo de un par de periodistas (Cortés, 2016; Pontevedra, 2012), de esforzados internautas (Proxecto Pepe Meijón) y de la nota puntual de un arqueólogo (Ayán, 2013), este legado colectivo no ha recibido hasta ahora mayor atención. No es un lamento, sino la condición de posibilidad de mis propias páginas. Pero sí expreso un deseo de alianzas, con la esperanza de poder consolidar este trabajo en relación con un tejido local existente de vecinos interesados en el conocimiento del legado de Pepito y en su protección.

Procede destejer las tramas de significados que informan el trabajo de Meijón sin pretextar su alteridad psiquiátrica, sino desde sus prácticas de escritura y grabado. Porque si es cierto que la primera resulta impensable, las segundas pueden ser objetivadas, al menos hasta un punto, a través de una serie de estrategias analíticas. Una de ellas, como ya se dijo, pasa por interrogar la relación entre obra y territorio, lo que requiere preparar un mapa y un inventario de la obra de Meijón, ubicando los lugares donde esta se conserva. A pesar de aún no haber completado esta tarea, ya puedo afirmar que el grueso de la producción de Meijón se condensa en un arco espacial que se puede recorrer en medio día y que, teniendo por centro el núcleo urbano de Marín, se extiende por los castros de los montes Pituco y Subidá, y por las parroquias de Mogor, Baguín y Setespadas. Hay otras intervenciones en núcleos más distantes por las colinas del Domaio, siempre hacia la ría de Pontevedra, pero solo en un caso hay noticia de inscripciones fuera de O Morrazo, específicamente en el Monte Acibal en Pontevedra ${ }^{2}$. Vemos asi que el trabajo de Meijón se condensa en espacios familiares. Como en los mapas de un Guy Debord que se hubiese venido a la aldea, la dispersión de grabados por todo el territorio comarcal nos permite dibujar el estilo de vida de su artista. Pepito entra y sale de Marín por la calle Calzada, avanza por corredoiras, deja atrás los lavaderos y se pierde en la vegetación de los castros, marcando con precisión sus avances con símbolos y letras, cruces y soles, calaveras, círculos concéntricos, dioses y demonios, como si fueran migas de hierro en la piedra, uniendo la casa con el yermo, la inmensidad con lo doméstico, para así no perderse en los caminos de la memoria, por su parroquia de voces, siempre a caballo entre el mundo de los vivos y los muertos, en su permanente guerra civil esquizofrénica.

De punta a punta, de Lourizán a Mogor, su espacio familiar se transita en pocas horas, aunque él lo volviese a recorrer durante varias décadas. A lo largo de las mismas, esta topografía tan densamente inscrita con dibujos y símbolos, se vio también atravesada por distintas capas históricas de hormigón y metales. Eso hace difícil hoy imaginar orgánicamente el territorio meijónico. Menos aún reconocer en él el entorno idílico de su infancia, tal y como, a principios del siglo $x x$, lo representaron los pintores galleguistas y los fotógrafos locales. Juntos construyeron los paisajes fundacionales de Marín, Lourizán y Estribela, y la poética costumbrista de la ría de Pontevedra. En conexión directa con la capital provincial, estos espacios constituían una región activa marcada por tres ejes: la fortaleza de su puerto pesquero, la emergente

2 El dato se lo debo a Celso Milleiro y José Luis Lede, quienes me pasaron las fotografías de su descubridor, Xesús Rodríguez Castro, lo que agradezco. 
condición turística de sus arenales y la presencia de Montero Ríos en el Pazo de Lourizán, con su influencia como centro político, diplomático, artístico y de investigación científica.

Estos ejes definen el entorno de Marín y la ría de Pontevedra hasta la guerra civil, tal y como se ve en las primeras postales del estuario. En sus paisajes se condensa una comprensión moderna de la gestión de un territorio en transformación, del que se enfatizaba el valor fundacional de su belleza indígena: las playas vírgenes, sus ricos arenales y el poder icónico de las masas forestales circundantes, atravesadas por tipos pintorescos (principalmente mujeres trabajadoras) o vaciadas y convertidas en espacios de reserva para la mirada turista. En ese mismo tiempo, dibujantes como el propio Alfonso R. Castelao y otros miembros de la Sociedad Arqueológica de Pontevedra inventariaron el patrimonio pétreo de la provincia y, de este modo, comenzaron a interesarse por los complejos rupestres de Mogor y por los cruceiros de la comarca, tan queridos para Pepito.

La conexión territorial de Marín con la capital provincial en este momento organiza un flujo de representación del espacio marinense en relación con las instituciones culturales pontevedresas, que podemos concebir en una órbita galleguista y republicana. Pero estos mismos flujos de institucionalidad adquieren un carácter marcadamente extractivo justo después de la guerra. En 1962, el robo del fascinante crucero de Estribela - hoy situado en el casco viejo pontevedrés- representa el ejemplo icónico de lo dicho. Ahí se cierra un entero ciclo de desposesión que tiene en la guerra su inicio y su desarrollo en la construcción primero de la Escuela Naval y después de la fábrica papelera ENCE-ELNOSA. Para ello, se cortocircuitaron las relaciones históricas existentes entre la comunidad y el territorio, restringiendo el acceso a los recursos comunales y alejando - por medio de infraestructuras-las parroquias marinenses de la cercana capital provincial. Por último, el flujo turístico se dirigió al norte de la ría.

Las rupturas de la guerra no suponen sólo una amenaza para la gestión tradicional del medio en clave comunitaria, sino también la interrupción de un modelo anterior de modernización, que llamaremos liberal-republicano. Este situaba en el centro la necesidad de mediación entre las necesidades, perspectivas e intereses de las comunidades locales y el establecimiento de políticas públicas de desarrollo, fundamentalmente sostenible. En ese modelo, las formas de innovación no fueron impulsadas de arriba a abajo (o no solamente), sino que fueron demandadas y diseminadas horizontalmente (Fernández Prieto, 1992). La poética del paisaje gallego anterior a la guerra, con su capitalización estética de un territorio bien ordenado, cuya propiedad resulta invisible - en gran medida por estar mancomunada- resulta consecuente con tal modelo. En ese contexto, donde la imaginación del paisaje y la intervención modernizadora sobre el territorio van de la mano, una serie de espacios naturales operan como laboratorios culturales al servicio del proyecto progresista. Ese es el caso del eje Marin-Pontevedra, donde se integra la reputación de Marín como pueblo desobediente, la importancia de la capital como cantera política, y el lugar central del Lourizán de Montero Ríos para las tradiciones de gobierno liberales. La superposición de violencias que terminará deshaciendo ese eje a partir de 1936 resulta elocuente a propósito de las potencias que allí se congregaban.

La historia de la violencia sobre el territorio donde - al mismo tiempo- esculpe sus petroglifos Pepito, comienza antes de la guerra, y puede entenderse (al menos en parte) como un castigo por la creciente politización de la villa de Marín, a la que sin duda llegaron ecos de la revolución soviética. Un claro precedente para los procesos de intervención espacial que caracterizan la transformación de la región bajo el régimen de Franco lo encontramos en la construcción del polígono de tiro naval, tras las huelgas de 1919, en respuesta a las capacida- 
des organizativas del mundo del trabajo, y especialmente de la Alianza Mariñeira. Realizado en 1920, será percibido como un dispositivo militar contrario a los intereses de los vecinos - y capaz de disparar sobre ellos- como cuenta Celso Milleiro (2014, 2017), cuyos trabajos me resultaron básicos para comprender las transformaciones de Marín). A partir de este campo de tiro, el militar Salvador Moreno asentará su influencia sobre la villa en los años de la dictadura de Primo de Rivera, y desde esa misma base se organiza el levantamiento franquista y la represión del verano de 1936. Por su importancia estratégica, en 1943 Franco decide convertir la base militar en la nueva sede de la Escuela Naval (anteriormente en Cádiz), la institución dedicada a la formación de los oficiales de la Armada española. Ello explica que, a día de hoy incluso, los diversos monarcas españoles siguen acudiendo a celebrar alli el día del Carmen en las vísperas del 18 de julio.

En los años cuarenta, la militarización de la bahía de Marín no se da como un hecho fortuito o desconectado de la violencia de 1936, sino como una causa y consecuencia de la misma. Así, cuando, en 1938, Franco concibió el emplazamiento de la nueva Escuela Naval, tuvo en mente tal vez la importancia de fortificar los estuarios gallegos a petición de Hitler, temeroso del poder naval inglés. Pero Franco ciertamente no olvidó la fama de Marín como villa peleona, y las azarosas jornadas en los puertos gallegos de julio de 1936, en los que el golpe de estado en Galicia podría haberse resuelto en una dirección muy diferente y, con ello, la guerra. Entre las consecuencias inmediatas de la construcción de la Escuela Naval, además de la transformación de la economía local y el daño causado la pesca, están la destrucción de varias playas, el bloqueo de la relación directa de Marín con el mar y la devastación de algunos petroglifos. A partir de ese momento, la presencia de barcos militares, los retratos del propio Salvador Moreno (la autoridad militar clave en el levantamiento franquista en Galicia), y la evocación de las rutas marinas como rutas de violencia, se convertirán en un motivo recurrente en la producción meijónica. Y, por si ello no bastase, la importancia de la Escuela Naval, llamada a transformar la articulación urbana y productiva de Marín y su cultura, está marcada en las pesadillas de piedra de Meijón, de manera transparente, por la continua mención a su escudo.

\section{Figura 4}

José Meijón. Plaza de la Constitución, Friso Oriental. Túnel de la Rúa da Calzada debajo de la Rúa da Ponte (Marín, Pontevedra). Detalle

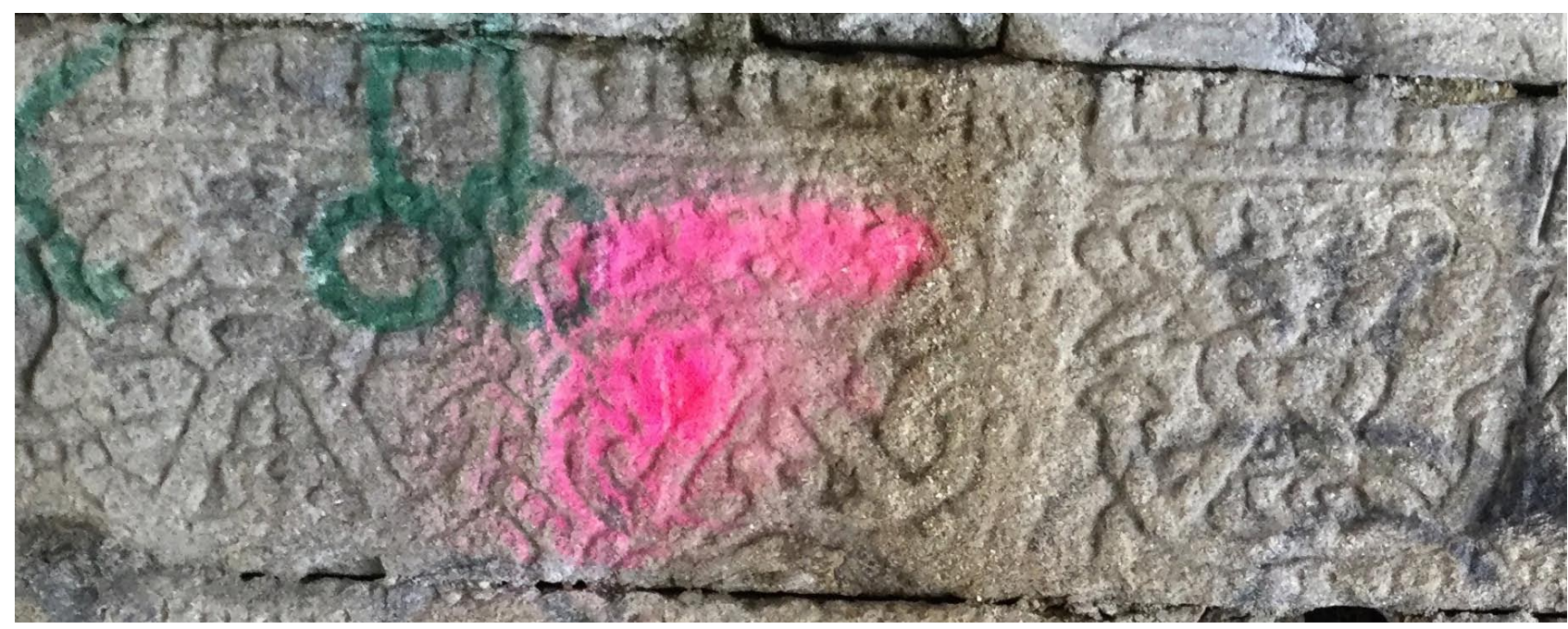

Fotografía del autor. 
Como nueva sede militar, Marín se convertirá en un escaparate del régimen. En los años cuarenta y cincuenta, la dictadura promovía una imagen humanista del complejo naval a través de narraciones como la famosa película Botón de Ancla (Torrado, 1948), donde los militares eventualmente operarían casi como un cuerpo civil de rescate al servicio de los pescadores locales en apuros. Pero, más allá de la propaganda oficial, la existencia de la base -y la violencia de su implantación- permitirá otras operaciones de reestructuración de un territorio de gran riqueza ecológica. Entre ellas, la ocupación de tierras comunales y arenosas, la construcción de carreteras militarizadas, la destrucción del patrimonio artístico y la imposición de un modelo de industrialización extractivo, contaminante e insostenible. Nada resume mejor este ciclo que la permanencia de la fábrica de papel ENCE-ELNOSA, el mayor legado de la dictadura en esas tierras aún a día de hoy. Para resistir su implementación, hubo importantes protestas capitaneadas por mariscadoras que el régimen no dudó en reprimir (Santiago, 2017). Y, para ello, usó a los mismos oficiales que en el cine ficticio salvaban la vida de sus hombres en mitad de las tormentas.

El ciclo de desestructuración territorial continuó en la democracia, con la construcción de carreteras e infraestructura pesada, a menudo de manera abiertamente ilegal. La densidad y el alcance del proceso merecerían un estudio aparte: hay hasta ocho ciclos de desposesión extractiva que, a lo largo de un siglo, colonizan un territorio, movilizando sus recursos al servicio de las élites españolas y del capital global. La guerra civil y sus masacres están en el centro del proceso, seguidas de una ocupación militar duradera. Sucesivas capas de infraestructura consolidan y naturalizan las formas de dominación y, en la práctica, constituyen barreras artificiales, muros y obstáculos poderosos para la organización local. Desaparecen los espacios públicos en un territorio donde las vías del tren de carga atraviesan plazas principales de parroquias. La fealdad, la violencia, la verticalidad con la que este espacio sigue siendo redefinido a día de hoy es heredera de décadas de violencia y desmemoria, y sólo el término "colonial» sirve para comprenderla. Me llevó años comprenderlo, pero esa es la razón por la que un niño criado a orillas del mar tenía que recorrer diez kilómetros para llegar a la playa. Porque la colonialidad es también, y sobre todo, una organización de la vida cotidiana.

De este territorio progresivamente intervenido, militarizado y desestructurado, Pepito sólo salió tres veces, que sepamos. La primera vez fue a la edad de veinte años, reclutado en 1921 para la guerra de Marruecos. Las otras dos fueron para ingresarlo en el temible Hospital Psiquiátrico de Conxo, en Santiago, de donde huyó a pie. Estas experiencias de alguna manera enmarcan el trabajo de Meijón a largo plazo. En Marín, a lo largo de una extensa posguerra, en un reducido territorio que, al tiempo, se agrieta y se violenta ante sus ojos, Meijón inscribe sus palabras como runas de piedra, como si quisiera curar las heridas del paisaje y proteger las lógicas autóctonas y los conocimientos que le son propios y antiguos. Ante la destrucción que comporta el desarrollo, Meijón opera con la intensidad psíquica de un chamán, y con la inequívoca modernidad de un cantero. Porque solo desde los saberes, las herramientas y las formas de trabajar de un oficio que, en lo fundamental, había cambiado muy poco desde el neolítico hasta sus días, es posible habitar una temporalidad como la que Meijón produce, desvinculada de los ritmos imperiosos del progreso, de sus urgencias en los cuerpos, y a través de las raíces antiguas de las formas rupestres y de las inmensas extensiones de tiempo denso que expresan. Es la profunda comprensión de un tiempo distinto, de un tiempo no coIonial, tiempo que Deleuze y Guattari (1973) vincularon tanto con el espíritu salvaje, como con la imaginación esquizofrénica, lo que nos permite enfrentar las brutales transformaciones del siglo con la confianza de que es posible comunicarse en ciclos milenarios gracias a la fuerza de la memoria que se guarda en las piedras. 


\section{LOS LABERINTOS DE MOGOR Y LAS FORMAS DE LA MEMORIA}

Es el momento de volver sobre la que podemos llamar catedral de los petroglifos neolíticos, el ya mencionado Laxe dos Mouros de Mogor, o piedra de los laberintos, para algunos una carta astronómica, para otros un portal chamánico y, en todo caso, un símbolo de la cultura gallega. La reproducción que aquí incluyo se corresponde con la disposición actual del lugar, que contiene una rampa de observación y un mapa informativo, detallado en la zona superior derecha de la imagen.

Figura 5

Anónimo y José Meijón. Laxe dos Mouros (Mogor, Pontevedra)

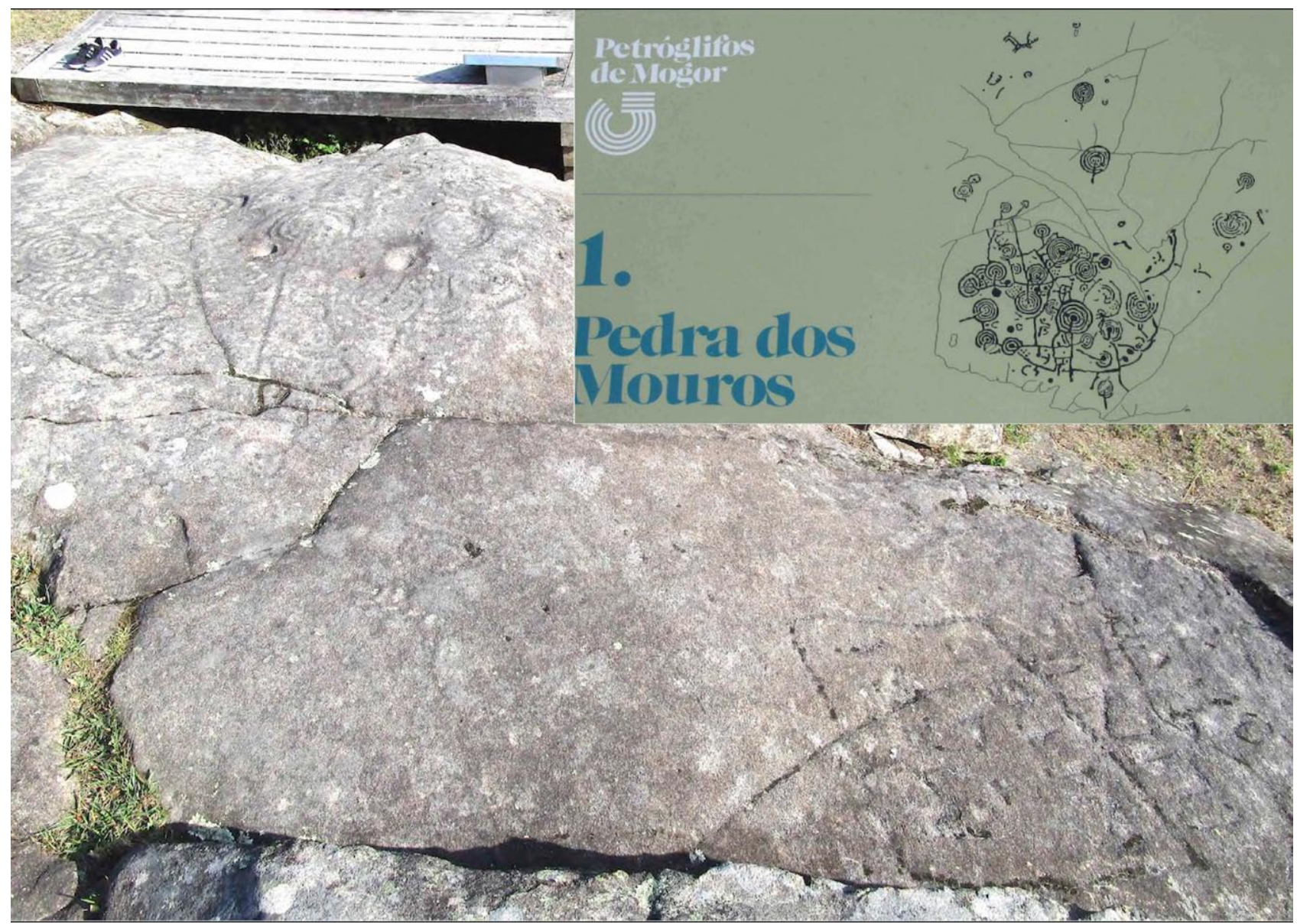

Fotografía del autor.

Su aspecto de espacio cuidado engaña: sólo hace dos décadas que estos petroglifos comenzaron a ser objeto de intervenciones patrimoniales de naturaleza proteccionista. Si atendemos al dispositivo interpretativo del cuadro superior el contraste aumenta, porque no reproduce con fidelidad los trazos que hay en verdad en la roca. No creo exagerado preguntarnos por la naturaleza de esa perspectiva. La colonialidad, como mirada, establece una distancia entre la representación orgánica y la pluralidad conflictiva de toda realidad sensible. No hay multiplicidad ni conflicto en el dibujo que los arqueólogos ofrecen a la contemplación de los 
turistas. En él, las formas que realmente existen en la ladera occidental de O Laxe dos Mouros han desaparecido. Porque lo que los arqueólogos eligen ver es algo diferente de la realidad estética de la piedra ofrece hoy en día al visitante. Si el mapa incluye los laberintos presentes en el margen izquierdo de la fotografía, los grabados del margen inferior derecho están ausentes. Los han considerado quizá como falsos petroglifos o, al menos, petroglifos modernos y, por tanto, faltos de interés patrimonial $y$, en consecuencia, invisibles.

Como era esperable, el autor de esos petroglifos subalternos no es otro que el propio José Meijón. Su intervención, desde una mentalidad arqueológica tradicional, obedecería a un impulso vandálico, que habría desprovisto al conjunto de su primitiva integridad. En el hacer de Pepito, sin embargo, sus grabados se vuelven legítimos precisamente en relación con el patrimonio prehistórico cuya proximidad reclaman. Quizá Meijón se sentía el heredero legítimo de esa tradición prehistórica y en sus derivas por bosques y por castros trataba de recrear sus rituales antiguos. Sus intervenciones, en todo caso, pueden comprenderse como parte de un diálogo más extenso entre tradición y vanguardia, entre petroglifos neolíticos y escultores modernos. Esta conversación había sido importante para los artistas e intelectuales gallegos de los años veinte y treinta, preocupados por la relectura de formas remotas como parte de una estrategia mayor de capitalización en clave nacional del patrimonio arqueológico y popular. No en vano los años en que Alfonso R. Castelao investigaba para su gran obra As cruces de pedra na Galiza (1949) -también en los alrededores de Marín- se corresponden con la época de formación de Pepito, quien, a su vez, provenía de una familia de canteros y él mismo estudiaría el oficio durante la República. No es improbable que vislumbrase a través de sus maestros la importancia del patrimonio comarcal de cantería (laudas, tumbas, cruceiros, iglesias, petroglifos...), y que aquellos le inspirasen la necesidad de establecer su propio diálogo.

Porque, aunque no me sorprende que Pepito interviniese en los entornos arqueológicos de Mogor o Monte Pituco, me impresiona que lo haga desde una voluntad memorial, inscribiendo la Guerra Civil en el tiempo mítico de las formas prehistóricas a través de petroglifos modernos. En lugar de laberintos, cuando dialoga con sus antepasados, Meijón esculpe lápidas, perfiles de tumbas con la probable inscripción INRI, la palabra MUERTE y, tal vez, escudos falangistas. De este modo, la guerra del 36 se vuelve parte de los laberintos sin fin de la Pedra dos Mouros, una nueva dimensión de su misterio, "casa» que deriva su violencia hacia los astros. Por medio de un polígono irregular, Meijón proyectaba la muerte y el dolor de su experiencia histórica en este receptáculo simbólico, inscribiendo el trauma de la represión en la larga duración del arte rupestre. Es justo ese mismo trauma lo que el arqueólogo elige no ver cuando vuelve invisible la escritura meijónica, borrando en el espacio su presencia en el tiempo.

Mi argumento se refuerza cuando comprendemos que las lápidas dos Mouros no serán las únicas intervenciones de Meijón en el entorno de Mogor. Cien metros más abajo, en los acantilados de la playa (farallóns), a mano derecha, encontramos un extenso mural. Un poema sobre la represión se extiende por la costa, en un área muy extensa, entre súplicas, símbolos bélicos y figuras inquietantes de dioses con rifles entre tumbas.

Como en un fresco apocalíptico, los grabados se concentran en un área popularmente conocida como $O$ Paredón, y constituyen una suerte de altar rupestre sobre la represión, que narra la llegada de extraños dotados de poderes sobrenaturales y del don de dar muerte, los cuales transformaron el paisaje costero de Marín en cementerio. Estas siluetas armadas miran al mar como esfinges o moáis, enigmas de un mundo desaparecido. Al pasar, reciben a los barcos que van al puerto, a los buques de la Armada que salen de la Escuela Naval. 
Figura 6

José Meijón. O Paredón, Punta Rabuñagatos, Playa Mogor (Pontevedra)

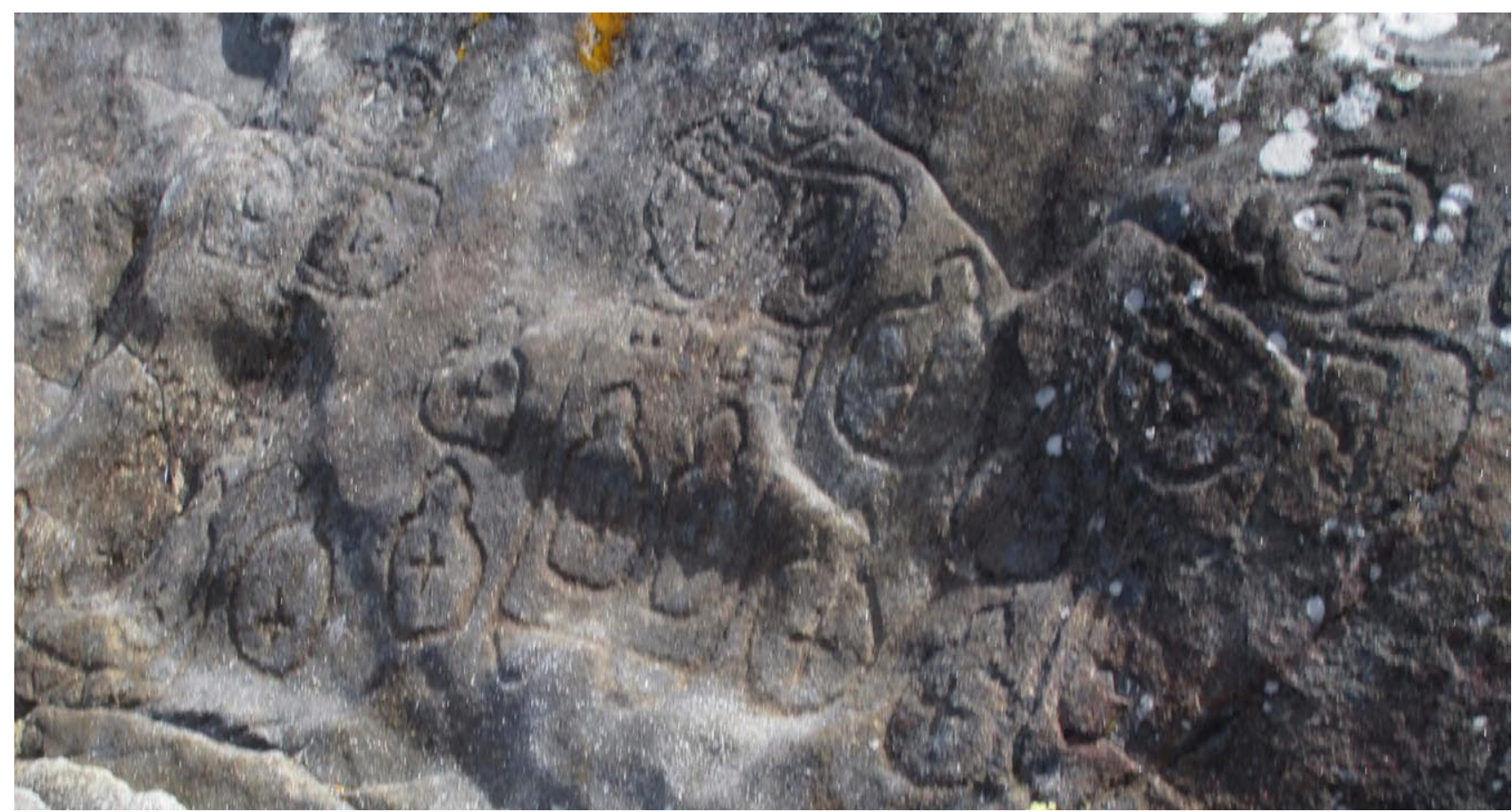

Fotografía del autor.

La dimensión conmemorativa del arte meijónico no solo se deriva —aunque también-, de su capacidad para inscribir en la roca referentes claros del franquismo vinculados con su organización militar, política o económica, como puede ser el caso de los buques de guerra, de las autoridades militares o de los símbolos falangistas. También tiene que ver con su habilidad para cruzar tiempos, y para traer de vuelta al mundo franquista -época durante la cual realizó la inmensa parte de su trabajo-, fragmentos del mundo anterior a la guerra. Su mirada desquiciada, proyectada en el reino de las piedras, no opera tanto fingiendo lo que no hay, escuchando lo inexistente, como a menudo se supone de un estado mental esquizoide. La mirada de Meijón logra, sobre todo, seguir viendo lo que ya no se ve. Justo al revés de lo que hace la mirada arqueológica colonial, Pepito mantiene la visión de un mundo que ha desaparecido en el mundo. Muestra, en el presente, la permanencia de un pasado que el presente tuvo que destruir para advenir. Al reunir los diferentes momentos del lugar en el mismo espacio, la página de la roca, el lugar del poema ocurre violentamente.

Porque, como ya he indicado, la región de Marín no siempre había sido un territorio herido y colonizado, sino también una activa región, social y políticamente diversa e innovadora, al menos desde los años setenta del siglo xIX y hasta la guerra civil. Importa recordarlo a la hora de medir el grado de violencia que la guerra necesitó para aflojar y deshacer los lazos políticos, religiosos y comunitarios de la parroquia. Las profundas transformaciones obradas en el conflicto enterraron hasta la memoria del mundo precedente, pero hay algunas señales evidentes que nos hablan de una sociedad civil plural y heterogénea con instancias de organización autónomas, en continuidad entre lo vecinal popular, lo político-sindical, y lo cultural-espiritual. No quiero caer en una lectura simplista o exótica de un lugar que, como cualquiera, tiene su propia complejidad interna, pero al estudiar su historia me llama atención la abun- 
dancia de instituciones civiles activas antes de la guerra. Ya mencioné algunos de los grupos involucrados en los nódulos locales del tejido social republicano. Porque, después de todo, lo que llamamos una república es, en gran medida, una red de redes civiles que, en algún momento de la década de 1930, participan o acompañan - y a veces también se enfrentancon una determinada institucionalidad afín (Labrador Méndez, 2010). Además de la influencia del núcleo político-científico-turístico-cultural-agrícola-escolar de Lourizán-Placeres, y de las alianzas político-sindicales de Marín con el entorno pontevedrés, vale la pena mencionar ahora también las actividades de la logia masónica Solón número 8. También las redes informales del mundo local del trabajo y la cultura, como las Sociedades Agrarias y las redes de la emigración. Pero, sobre todo, este es el momento de reconocer la centralidad de un actor aún no mencionado: las comunidades protestantes de Marín y Seixo que, con apoyo inglés, y desde fechas muy tempranas, fueron fundamentales en la articulación local de una esfera educativa autónoma, más allá del control de la Iglesia católica (Milleiro y Moreira, 2017).

\section{Figura 7}

Iglesia Evangélica de Marín (Pontevedra). Detalle de la fachada

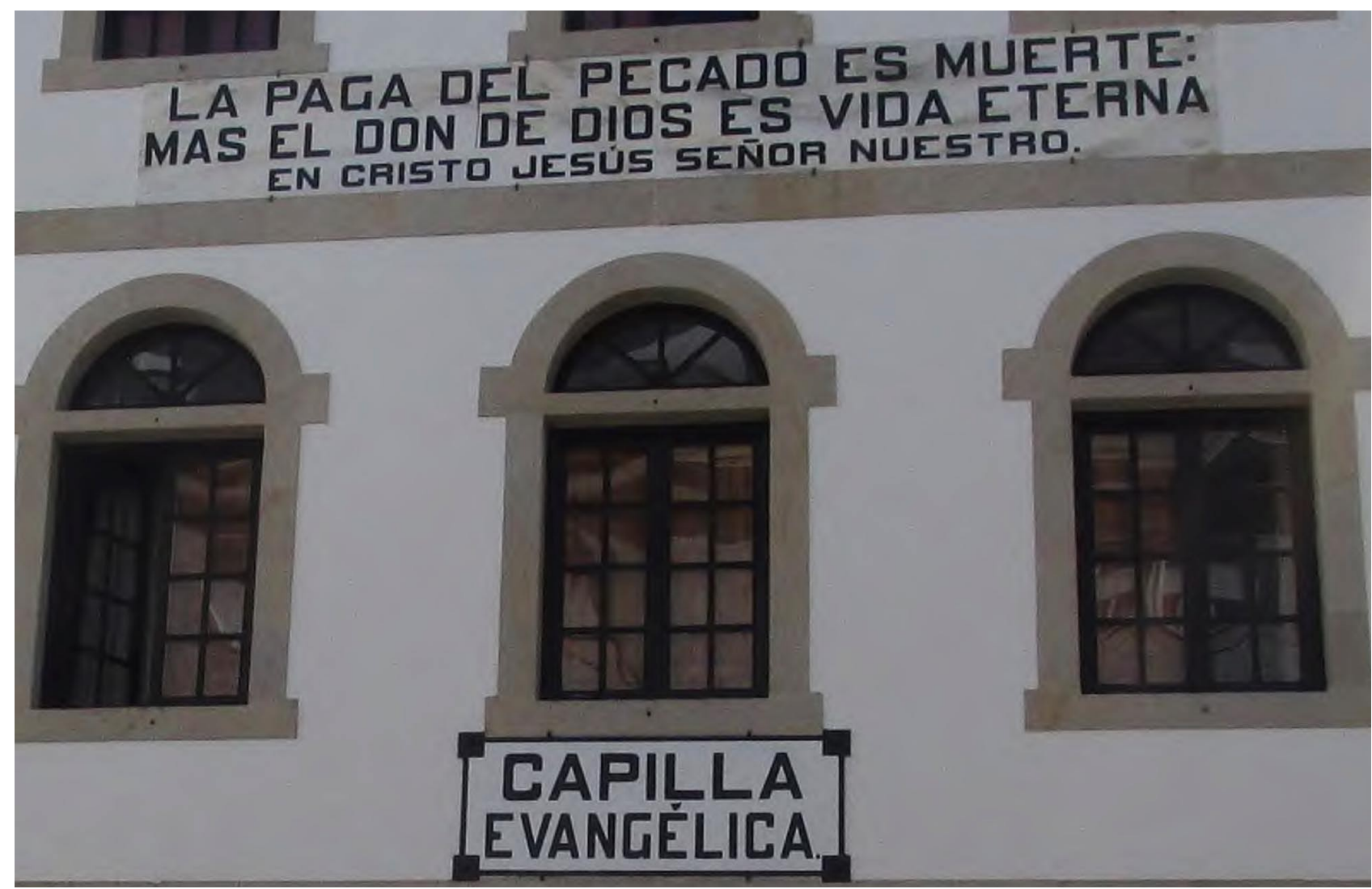

Fotografía del autor.

En la larga duración, la vida histórica de una comunidad viene marcada por los efectos de interrupciones abruptas, cesuras y caminos históricos suprimidos. Construir instituciones, prácticas, modos de ver y de pensar propios requiere mucho tiempo, pero estos pueden arrasarse en un verano de terror, porque los tiempos de construcción democrática son lentos pero los efectos de la violencia política se manifiestan de inmediato. En este sentido, aún no 
conozco el trabajo que, en el contexto ibérico, explique con cierta sistematicidad los procesos que logran hilar, por debajo, secretamente, las memorias de la Primera República con los trabajos para la construcción de la Segunda. Este trayecto histórico nos remite, de un lado, a la necesaria transmisión de saberes y experiencias a lo largo de tres generaciones y, de otro, a la construcción de espacios de autonomía. En este sentido, Marín ya se había caracterizado como una villa de avanzada en términos de reclamación de derechos y producción de cultura republicana en el entorno del Sexenio Democrático. La emergencia de una sociedad auto-organizada, parcialmente secular y multiconfesional, en el contexto peninsular decimonónico, involucra centralmente el campo educativo. Y el elemento evangélico es clave para explicarlo, en una villa conocida por entonces en España como la «Roma Protestante», donde las Asambleas de Hermanos abrieron las primeras escuelas seculares y mixtas, décadas antes de la llegada de la Segunda República. En ellas pudo estudiar Pepito.

Las obras de Marcos Gago $(2007,2017)$ muestran la rica existencia en Marín de grupos protestantes y dan una medida de su fuerza. Estos tejieron, desde Pontevedra hasta Bueu, una activa red que, en los años de la infancia de Meijón, construía espacios pedagógicos, asociativos y espirituales liberados del Estado y de la Iglesia Católica, desde claves de autonomía popular. Las fuerzas que el Franquismo coaligó vieron el protestantismo como una clara amenaza y, así, los líderes protestantes fueron señalados, el culto perseguido y las iglesias cerradas (Gago, 2017). Sin embargo, y desde mi punto de vista, la verdadera importancia del tejido protestante radicaba no solo en su entidad y cohesión interna, sin duda admirable, o en la perseverancia de sus miembros en las condiciones más adversas. Más importante, la presencia del mundo evangélico en ciertos lugares de la geografía peninsular favorecía las experiencias republicanas de base asamblearia, gracias a su capacidad para establecer sinergias con otros movimientos civiles en sus localidades, ya sean sindicatos, asociaciones, partidos políticos, logias masónicas o instituciones culturales como escuelas. El protestantismo conlleva un repertorio de prácticas organizativas antiautoritarias y un lenguaje moral alternativo al católico, basado en una espiritualidad distinta. Todo ello facilita la creación de contrapoderes. Algo de esto se dio en Marín en el primer tercio del siglo, una sinergia creativa entre movilización política, innovación pedagógica y transformación cultural de la que hoy sabemos muy poco.

Es cierto que, en Marín, las formas más violentas de represión no se dirigieron directamente contra miembros de la comunidad protestante - quizá sólo por estar localmente protegidos por el consulado inglés-, sino contra el tejido sindical local y contra las autoridades republicanas. En el verano de 1936 en Marín se sucedieron de modo indiscriminado palizas, destierros y encarcelamientos. Además, fueron asesinados al menos el alcalde republicano y dos funcionarios municipales, dos mujeres carismáticas de entre las lavanderas, el presidente del gremio de pescadores, el representante de la juventud socialista y el presidente de la Irmandade de Canteiros, quien, por cierto, fue el maestro de José Meijón. Esta violencia selectiva se dirigía a decapitar las instituciones y los movimientos sociales, buscando generar el clima de terror necesario para la imposición sin resistencia de un sistema autoritario. En este contexto, la pertenencia al mundo republicano se convirtió en una señal de desgracia ante la cual la negación y el olvido constituyen estrategias de supervivencia.

Esto también es cierto en el campo religioso, especialmente cuando, como digo, el protestantismo en Marín no era solo una religión sino una cultura y un entorno asociativo. Pero después de la guerra, sus practicantes serán marcados como una minoría en la parroquia y sus iglesias cerradas (menos una, a petición del consulado inglés, convertida en la supuesta prueba de la libertad de cultos en la España de Franco). Más allá de este núcleo, se reescribie- 
ron las filiaciones y alianzas dentro y fuera de la comunidad protestante. Por eso es tan difícil, sino imposible, reconstruir los lazos políticos y religiosos existentes entonces, porque las marcas de afinidad y pertenencia han desaparecido. Quizás eso fue lo que también sucedió en el entorno de los Meijón Area. Porque la familia materna de Pepito, incluido su abuelo, era protestante, pero eso no impidió que Meijón y sus hermanas fueran enterrados, a finales de los años 70, como católicos.

No es fácil reconstruir esta historia en sus detalles biográficos, donde hay pistas que apuntan a la conexión familiar con el protestantismo, también entre las hermanas de Pepito. Pero en lugar de especular partiendo de indicios y de memorias orales, es preferible interpelar a Meijón a propósito de la presencia del mundo evangélico en sus grabados. Esta no resulta menor: las menciones a "Lutero pastor protestante" son bastante comunes, como también los rótulos de "Jehová» en lavaderos, que Pepito transforma mediante sus inscripciones en fuentes bautismales. También son relevantes las repeticiones de algunos versículos bíblicos, particularmente aquellos con los que la comunidad evangélica adornaba el exterior de sus templos. Romanos 6:23 será el principal de estos pasajes, que Pepito compulsivamente reescribe, donde se afirma que "la paga del pecado es muerte, pero el don de Dios es vida eterna en Cristo Jesús Señor nuestro».

\section{Figura 8}

José Meijón. Versículos. O Pereiro, Capilla de Sandegho (Pontevedra)

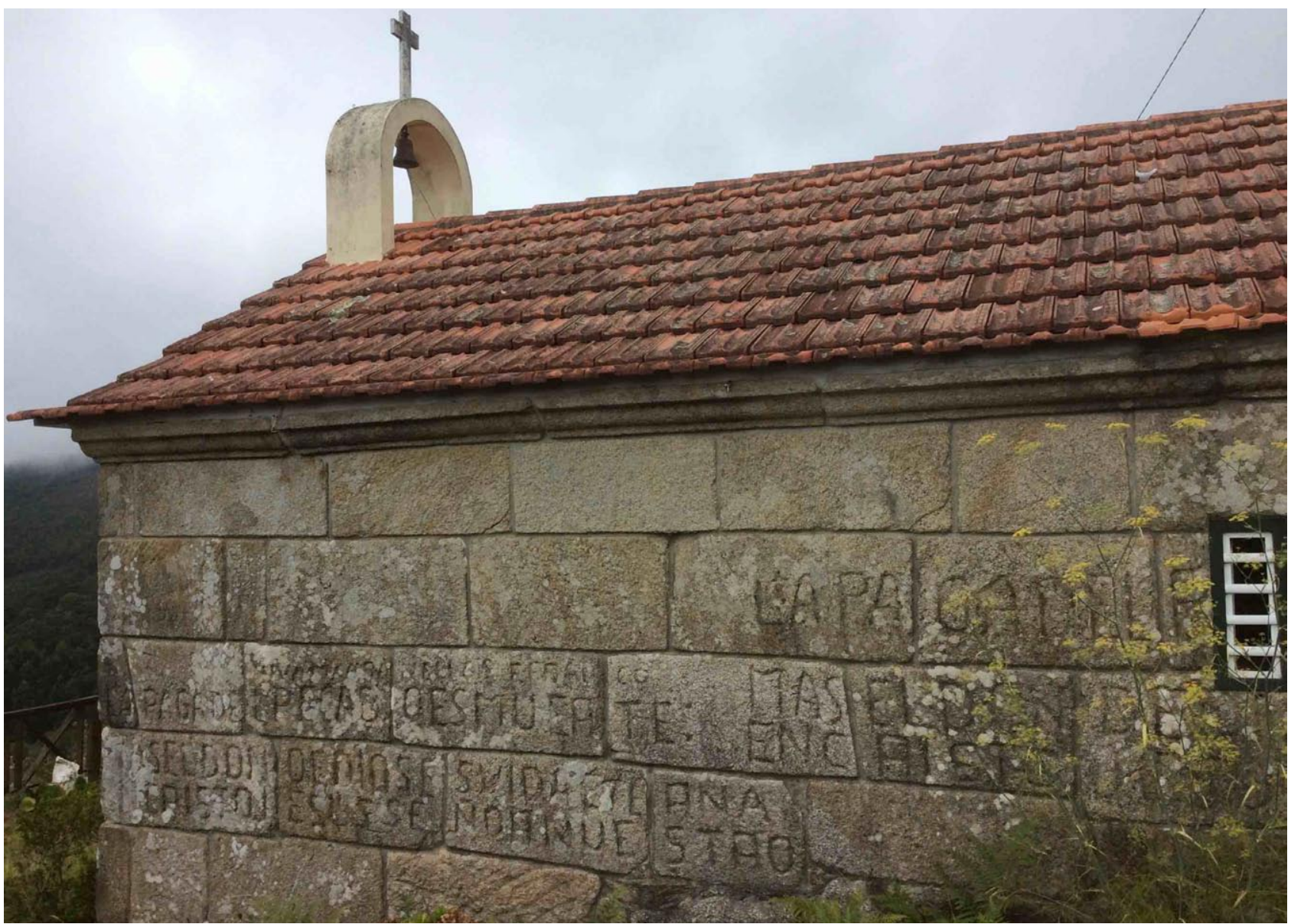

Fotografía del autor. 
Las iglesias evangélicas - sobrias en su estética- adornaban sus fachadas con citas de la Biblia. Estas fueron borradas durante la guerra civil y solo recuperadas después de 1978 . $R e-$ pintadas las iglesias, tal discontinuidad hoy resulta indetectable, pero, bajo el franquismo, la ausencia de las inscripciones sería significativamente política. Desde ahí debemos iluminar la obsesión de Meijón por esos mismos versículos borrados, que reescribe una y otra vez en las paredes de su parroquia. No sobre los muros de las iglesias protestantes censuradas. Hizo algo más radical y, en cierto modo, iconoclasta: grabó las mismas citas de la Biblia en las paredes de los templos católicos locales.

Las escribió en una docena al menos de capillas, cementerios, iglesias y lavaderos. A golpe de martillo, de este modo, "evangelizaba" "convirtiendo" los lugares de culto populares en espacios memoriales. Frente a la radicalización del nacional-catolicismo, Meijón inscribía públicamente en las paredes de su comarca la existencia larvada de una religiosidad alternativa y, con ella, de otras formas de comunidad, de otros proyectos políticos, que, todavía, vivían en el recuerdo.

Meijón invirtió demasiada energía en reescribir los signos de la memoria en el territorio de la represión como para que hoy ignoraremos el sentido de su gesto. Usando los lenguajes de la cantería y del arte rupestre, Pepito dio una forma a la violencia represiva aplicada sobre su entorno, culturalmente invisibilizada. Frente al silencio, y al borrado iconográfico, Meijón traía de vuelta los nombres de las instituciones populares del Marín republicano. No solo las formas de espiritualidad y convivencia protestantes que parte de su familia materna había practicado, sino también las mismas instituciones republicanas con las que colaboraba su familia de padre, y en las que él mismo había militado. Este es el caso específico del Comité Local de la Federación Socialista de Trabajadores y de la Fraternidad de los Canteros, cuyos símbolos -escuadras y compases, conchas jacobeas y la mano con la daga que exige venganza - reencontramos a menudo en las inscripciones de Pepito. Otros colectivos memorializados son el Ayuntamiento Republicano (Casa Consistorial) y la Sociedad de Maquinistas y Fogoneros. Una y otra vez reaparecen dos manos en apretón, con ellas se representa la unión de los dos principales sindicatos del momento (UGT y CNT), pero también se identifican varias logias gallegas.

Figura 9

José Meijón. Federación Obrera, Comité Local.

Paredes del Antiguo Matadero de Lapamán (Pontevedra). Detalle

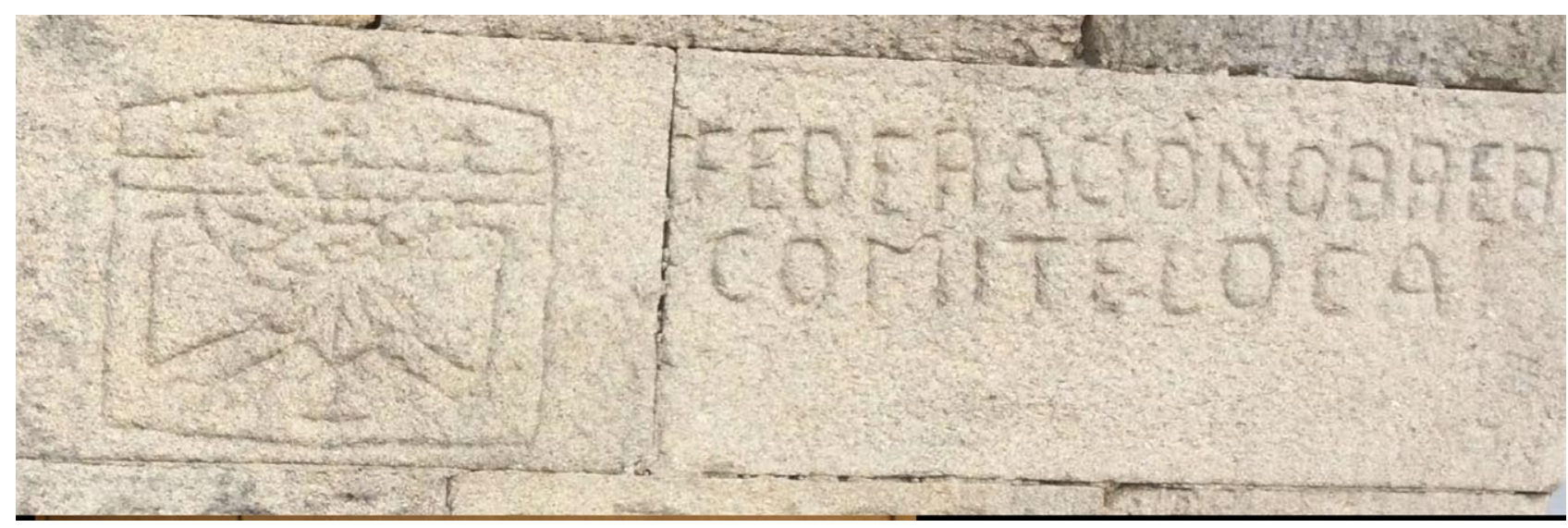

Fotografía del autor. 
Otras marcas de masonería - como el compás superpuesto con la escuadra- se confunden fácilmente con las laudas y emblemas propios de los canteros. Pero hoy todos estos trazos son mudas voces de piedra. El universo que Pepito estaba tratando de recuperar -0 , al menos, no perder de todo- se ha alejado aún más del nuestro, como si su trabajo, lejos de traer de vuelta un mundo ya deshecho, solo pudiese dar cuenta de su desaparición final.

\section{CODA: CINCEL EN LA PARED DE LA MEMORIA}

Una forma de explicar la guerra civil en el contexto de Marín pasa por plantear la existencia de dos formas de modernidad en conflicto, que implican a la vez dos imaginarios culturales y dos modos de organización territorial en competencia. Más específicamente, cabe describir el levantamiento franquista como una reacción autoritaria, de matriz nacional-católica, que buscaba abortar las posibilidades abiertas por las formas de asociación republicana, en sus capacidades democratizadoras, de socialización del poder e imaginación colectiva de la ciudad y el territorio. Esta estrategia de guerra se experimenta traumáticamente en la escala local, porque cada uno de los actos de violencia dirigidos contra personas e instituciones concretas opera sobre el tejido afectivo de la comunidad en su conjunto. En Marín, durante el verano de 1936, un entero universo multiconfesional, galleguista, trabajador y participativo se interrumpió brutalmente. La violencia del golpe impulsó la contrarrevolución política y religiosa, pero no solo. También favoreció el inicio de un nuevo ciclo económico de carácter extractivo, propiamente colonial en sus relaciones con el medio ambiente y con los desplazamientos entre territorios y recursos. El terror dirigido contra las formas de organización política propias de las culturas locales constituye un primer paso, necesario pero no suficiente, para el establecimiento vertical de nuevos modos de producción desposesivos.

Es un buen momento para volver sobre el texto escultórico que analizamos al comienzo de estas páginas, el poema logográfico de Meijón escrito en las paredes del llamado «túnel de la memoria» de la calle Calzada de Marín [ver figura 3]. Aunque leímos solo un fragmento del mismo, esta pieza, como dije, forma parte de un dispositivo mayor, un friso doble que ocupa la totalidad del túnel, y parte de sus exteriores. Las inscripciones incluyen versos, palabras y figuras alegóricas. En uno de sus extremos encontramos incluso retratos de los perpetradores, como del mencionado Salvador Moreno, golpista y Ministro de la Marina de Franco, que guio la militarización de la región y la creación de la Escuela Naval. Aunque en general resulta difícil fechar las creaciones de Pepito, en este caso tenemos un indicio valioso. Porque aunque no sea posible asegurar que el trabajo se realizó después de la muerte de Franco, es cierto que el nombre que Meijón eligió para identificar su entero túnel no es casual. Lo llamó: «Plaza de la Constitución».

La primera vez que lo vi imaginé que Meijón, quien moriría en 1980, quiso rendir así con una última obra su tributo a la transición democrática y a la Carta Magna. En relación con el metarrelato de la época, parecería tener su sentido cerrar el túnel de los horrores de la guerra civil con una referencia feliz a la Constitución. Aunque quizá la obra de Pepito fuese ligeramente anterior, esta era una hipótesis asumible, aunque también desconcertante. Para cerciorarme investigué el callejero de la villa. Porque como cuando Meijón incluía nombres propios o topónimos en sus obras siempre se refería a entidades realmente existentes en el mundo, entonces debía haber una Plaza de la Constitución real que sirviese de soporte al título de su obra. Sin embargo, la actual Plaza de la Constitución de Marín se inauguró un cuarto de siglo más tarde 
de la muerte de Pepito, lo que no se corresponde con el grafiti. Me hizo falta otro tipo de búsquedas para descubrir una verdad consistente con el personaje, y con su arte, pero no menos sorprendente. En sus últimos años de vida, al final del franquismo, Meijón, desde su mundo de voces, aún tenía la suficiente lucidez para recordar, en tiempos de olvidos, que una vez, décadas atrás, había habido otras constituciones. Y que, en homenaje, se le dio ese nombre a una plaza. Porque, aunque entonces pocos lo recordasen, en el Marín republicano sí había otro lugar que respondía al mismo topónimo que Meijón dio a su túnel. Pues, en el centro del pueblo, frente a la iglesia principal, la hoy conocida como Plaza del Reloj, en los años de la Segunda República se la llamó, precisamente, Plaza de la Constitución. Pero de la Constitución de 1931.

Figura 10

José Meijón. Plaza de la Constitución, entrada norte.

Túnel de la Rúa da Calzada debajo de la Rúa da Ponte (Marín, Pontevedra). Detalle

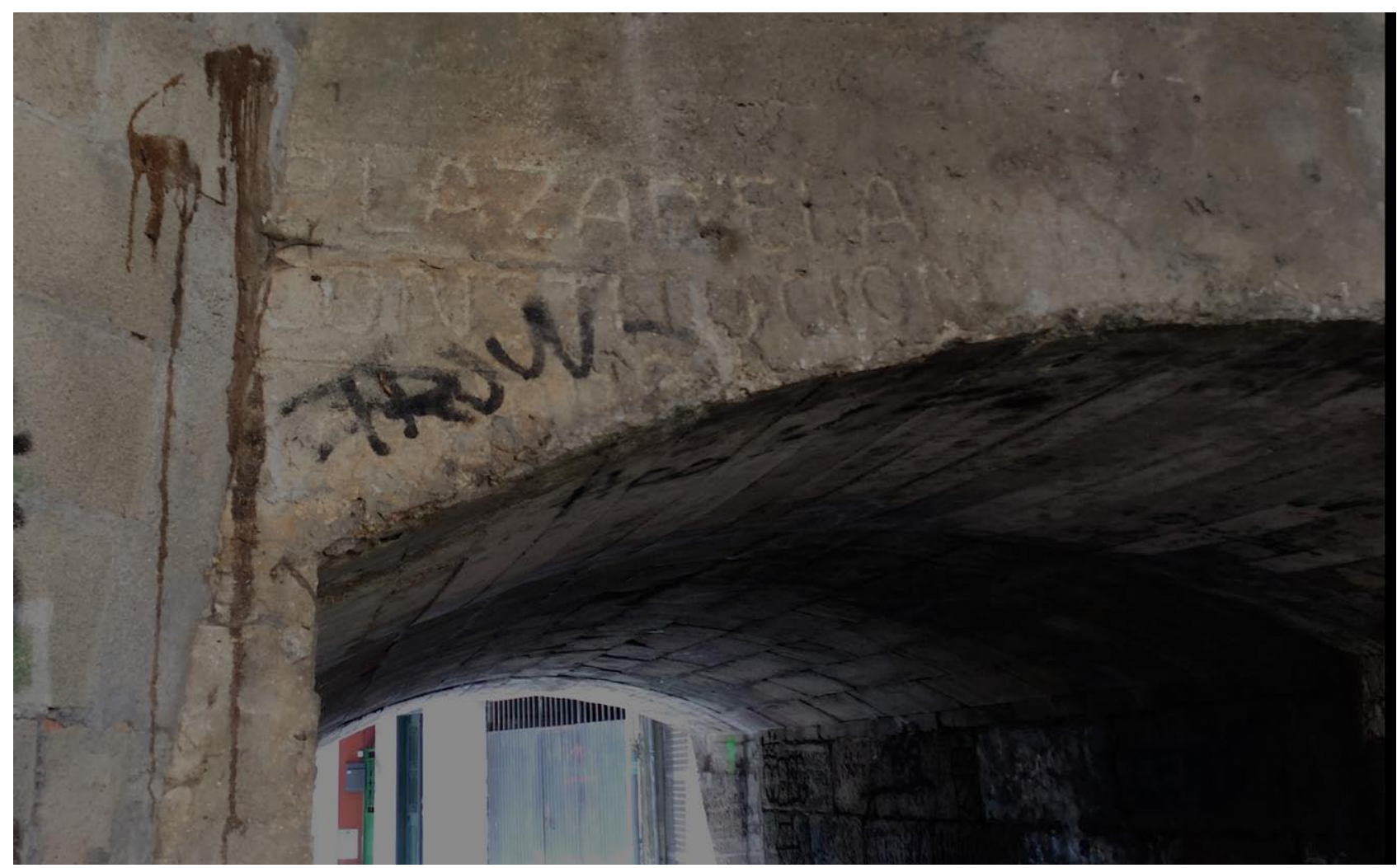

Fotografía del autor.

Pepito Meijón cubrió su territorio con marcas de lo ausente, honrando la memoria de las instituciones y de los mundos democráticos que una vez lo constituyeron al servicio de las aspiraciones civiles de su comunidad. Al tiempo supo darle un lugar a la violencia que lo atravesó hasta refigurarlo, violencia que, por fundacional, se había vuelto invisible. Gracias a su tarea, tal vez Meijón logró tener a raya a los demonios que lo atormentaban por dentro. Quizá él se imaginaba transitando caminos entre el pasado y el presente, haciendo de sus viajes erráticos por las colinas, ritos de restitución de las heridas del tiempo. Por medio de esas derivas Pepito suturaba los desgarros reinscribiendo curativamente el dolor como redención en la naturaleza. Así, cuando buscaba con mis padres el emplazamiento del Pozo da Revolta, uno 
de los lugares más oscuros en la geografía de la represión local, donde mataron a las lavanderas María A Capirota y Lola de Cangas, descubrimos que alli desembocaban las aguas de un regato. Curso arriba llegamos al Lavadero de Don Pedro, donde Meijón inscribió el nombre de Jehová entre signos mágicos, como si quisiera transformar estas aguas públicas en un nuevo Jordán. Era así como Pepito lavaba con las aguas de la memoria la sangre de las matanzas.

Hay un último espacio de la geografía meijónica con el que quiero cerrar estas páginas. Se encuentra en los muros del cementerio municipal, otro de los patíbulos informales de la represión franquista en Marín. En diciembre de 2018 pude asistir a un acto de homenaje a los muertos de O Morrazo, convocado por las Asociaciones para la Recuperación de la Memoria Histórica de Bueu y de Marín.

\section{Figura 11}

Placa. Colocada por la Asociación para la Recuperación de la Memoria de Marín. Homenaje a los Ejecutados en el Cementerio Municipal de Marín (Pontevedra), 23 de diciembre de 2018. Muro Sur. Detalle

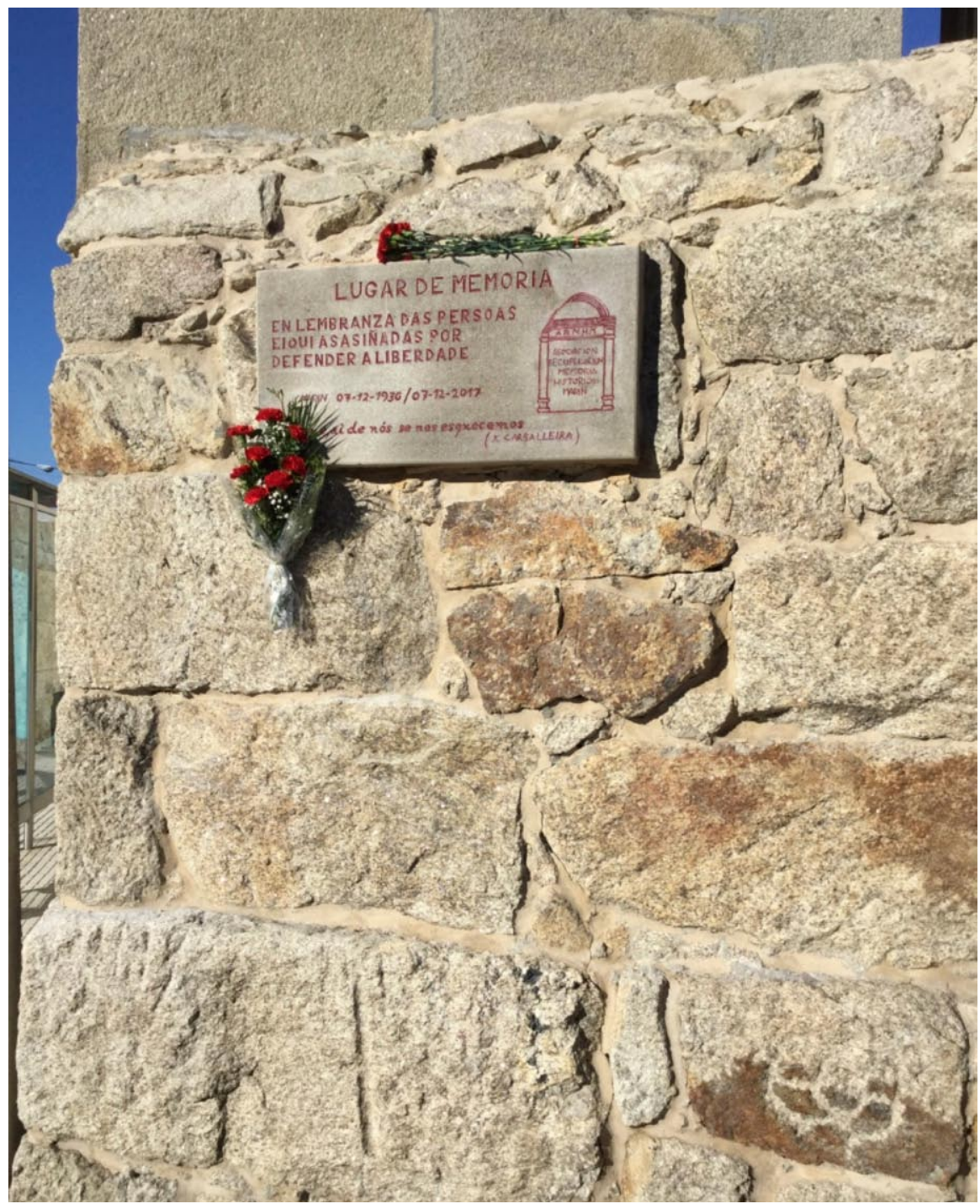

Fotografía del autor. 
Tras una charla en la Biblioteca Municipal, subimos en comitiva hasta el camposanto para descubrir una placa que reconoce el lugar como un espacio de muerte y dolor, pero también de memoria y compromiso. Pusieron flores, cantamos el himno gallego, nos abrazamos, algunos lloraron. Había tomado ochenta años dignificar este lugar, pero al final lo logramos. Pero a pesar de mi simpatía absoluta por un acto en el que participé sin la más mínima distancia, con emoción y compromiso, algo de todo aquello me inquietaba. La inquietud siguió creciendo hasta que por fin pude darle salida. Porque resulta que la placa conmemorativa fue colocada encima de las antiguas inscripciones de Pepito. Y, al prestarle atención, se hizo evidente que la pared entera del cementerio era a su vez un inmenso memorial meijónico, plagado de figuras infernales, lápidas, oraciones, soles, símbolos, nombres republicanos y citas evangélicas. Pero para nosotros, ciudadanos contemporáneos, simpatizantes, académicos o activistas de la memoria histórica, resulta difícil ver las marcas de las memorias preexistentes. Somos un poco como los arqueólogos que deciden cómo hace falta ver los laberintos de Mogor, porque nuestras formas de mirar, tal vez para nuestro pesar y en contra de nuestra voluntad incluso, son herederas de las mismas violencias que han devastado otras formas del mundo que ya no están en este, y son también las hijas de la organización de sus saqueos.

Figura 12

José Meijón. La mano negra.

Muro principal del Cementerio Municipal de Marín (Pontevedra). Detalle

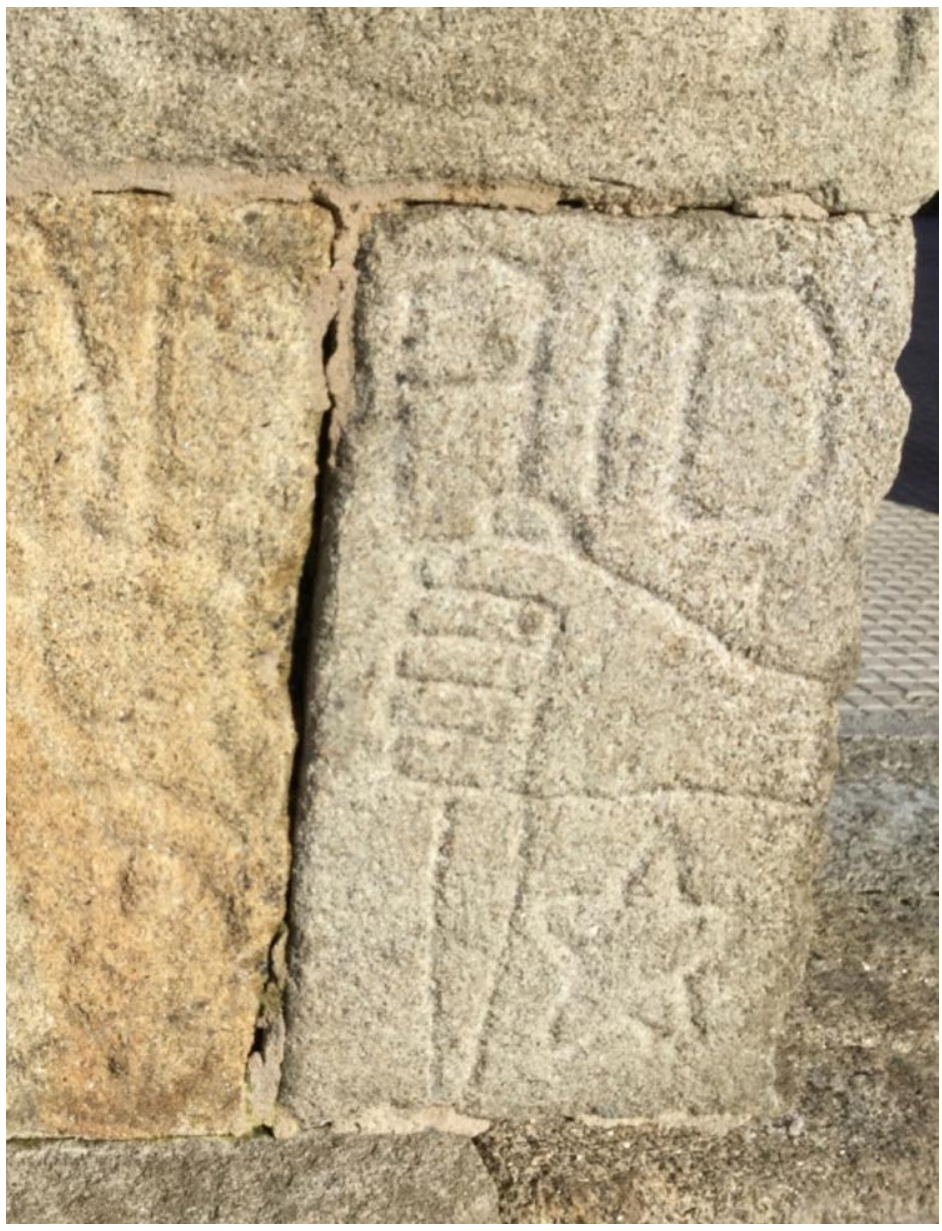

Fotografía del autor, 23 de diciembre de 2018. 
Lo que vemos, o no, culturalmente, depende en primer lugar de las rupturas y la violencia que hemos aprendido a no ver. También cuando queremos recordar o conmemorar las razones y causas de aquellos que fueron devastados por este proyecto colonial que llamamos progreso. Por eso, paradójicamente, muchos de nuestros actos conmemorativos hacen invisible el trabajo de quienes lo apostaron todo a inscribir una marca de la presencia de un mundo que tuvo que ser destruido primero para poder luchar hoy por un recuerdo. Las historias que hoy nos contamos deben aprender a no borrar los últimos residuos del universo que dicen querer honrar. Tienen que usar aquellas formas extrañas que aún laten en los huecos de la memoria, como un pie contra la jamba de la puerta del tiempo que se cierra.

\section{REFERENCIAS}

Ayán, X. (2013). Pepito Meijón. Tres entradas. A Lucerna do Abade, Maio 15-19.

Castelao, A. (1949). As Cruces de Pedra na Galiza. Buenos Aires: Nós.

Cortés, N. (2016). O incomprendido Pepe Meijón. Diario de Pontevedra, Ago. 28.

Delgado, E. (2014). La nación singular. Fantasías de la normalidad democrática española (19962011). Madrid: Siglo XXI.

Deleuze, G., y F. Guattari (1973). El anti-Edipo. Capitalismo y esquizofrenia. Barcelona: Barral.

Fernández Prieto, L. (1992). Labregos con ciencia. Vigo: Ed. Xerais.

Ferrándiz, F. (2014). El pasado bajo tierra. Exhumaciones contemporáneas de la Guerra Civil. Madrid: Anthropos.

Ferrándiz, F., Robben, A., y Wilson, R. (2015). Necropolitics: mass graves and exhumations in the age of human rights. Philadelphia: University of Pennsylvania Press.

Gago, M. (2007). Enrique Turrall. En los campos de Galicia. Marín: Publicidad y Artes Gráficas Dibay.

Gago, M. (2017). Persecución contra os protestantes na Guerra Civil e no franquismo. Asociación pola Recuperación da Memoria Histórica de Marín (Pontevedra), 15 Oct.

Hernández, J.F. (2013). Singular Spaces: From the Eccentric to the Extraordinary in Spanish Art Environments. San Jose: San Jose State University.

Labrador Méndez, G. (2010). Teleliberalismo o república inalámbrica? Hispanic Review, 78(4), 579-582.

Mbembé, A. (2001). On the postcolony. Berkeley: University of California Press.

Mbembé, A. (2003). Necropolitics. Public Culture, 15(1), 11-40.

Milleiro, C. (2014). Rúa do polígono de tiro naval Janer. Pontevedraviva.com, Feb. 19. Disponible en: https://pontevedraviva.com/opinion/926/celso-milleiro-poligono-tiro-navaljaner/ 
Milleiro, C., y Moreira, X.M. (2017). Memorias de sal e terra: o ensino no Concello de Marín (18671940). Pontevedra: Diputación de Pontevedra.

Pérez Ocaña, Ó.L. (2011). Land Art en España. Rubí: Ediciones Rubeo.

Piedras Monroy, P. (2012). La siega del olvido. Memoria y presencia de la represión franquista. Madrid: Siglo XXI.

Pontevedra, S.R. (2012). El hombre que nació 4.000 años tarde. El País, Mayo 21.

Ramírez, J.A. (2013). Escultecturas margivagantes. La arquitectura fantástica en España. Madrid: Siruela.

Santiago, L. (2017). Paraíso roubado. Pontevedra: Asociación pola Defensa da Ría.

Torrado, R. (1948). Botón de Ancla. España: Suevia Films. 